\title{
Thermodynamic Analysis of the Experimental
}

\section{Equilibria for the Liquid-Phase Etherification of}

\section{Isobutene with $\mathrm{C}_{1}$ to $\mathrm{C}_{4}$ Linear Primary Alcohols}

Jordi H. Badia, Carles Fité*, Roger Bringué, Eliana Ramirez, Fidel Cunill

Chemical Engineering Department, Faculty of Chemistry, University of Barcelona, Martí i

Franquès 1, 08028 Barcelona, Spain

\section{ABSTRACT}

The chemical equilibrium of the liquid-phase syntheses of 2-methoxy-2-methylpropane (MTBE), 2-ethoxy-2-methylpropane (ETBE), 2-methyl-2-propoxypropane (PTBE), and 1-tertbutoxybutane (BTBE) by reaction of isobutene with methanol, ethanol, 1-propanol, and 1butanol, respectively, has been studied. Four different ion exchange resins as the catalysts, and two different reactor systems, namely a batch reactor and a setup of tubular reactors, were used. Temperature and pressure were in the range 313-383 $\mathrm{K}$ and 1.5-2.0 MPa, respectively. MTBE and ETBE synthesis reactions experiments were carried out mainly to validate the reliability of the reaction systems. Experiments in PTBE and BTBE etherifications allowed estimating thermodynamic properties for those reactions and involved species, namely molar standard enthalpy and entropy changes of reaction and molar enthalpy change of formation of the four ethers. Comparison of estimated reaction thermodynamic values among the homologous series of linear alcohols, and with results quoted in the literature, when available, has been made. 
KEYWORDS: Thermodynamic properties, etherification, isobutene, primary alcohol, ion exchange resins

\section{INTRODUCTION}

Experimental studies on thermodynamic properties concerning promising processes are mandatory to determine their viability. In this sense, all major industrially-operated production processes have to be preceded by thorough studies on their equilibrium conditions. Recent examples of this fact, from several disciplines, would be the synthesis of graphene ${ }^{1,2}$, pharmaceutical drugs design ${ }^{3,4}$ or novel biofuels production ${ }^{5-7}$.

Regarding biofuels, new legislation in European countries is pushing ahead with next generation fuels to reinforce the struggle started by the EU with directives 2009/28/EC and 2009/30/EC, which promote the usage of renewable sources and establish fuel reformulation main guidelines. Among fuel additives that help reaching the required standards, oxygenate ethers arise as a feasible alternative.

Oxygenate additives like methyl tert-butyl ether and ethyl tert-butyl ether, obtained by isobutene etherification with methanol and ethanol, respectively, have been already studied since they have been produced worldwide for decades. However, the production of heavier ethers from alkene etherification with larger primary alcohols has been scarcely studied. An increase of the number of carbon atoms of ethers leads to a decrease of the vapor pressure and the solubility in water, and to an increase in its boiling point ${ }^{8,9}$. These are desirable characteristics for fuels, because they entail a reduction of evaporative emissions and risk of water contamination, and because they contribute to a dilution effect of some harmful components, i.e. aromatics.

Larger linear alcohols, such as 1-propanol or 1-butanol, have been extensively produced at industrial scale by the oxo process ${ }^{10-12}$. Biomass-based production routes have also been 
studied, namely the condensation of bioethanol and/or biomethanol (Guerbet Catalysis) and the ABE fermentation ${ }^{13,14}$. In this case, ethers from larger alcohols can be considered to contribute in accomplishing the biofuel target. Prior to scale-up studies on the feasibility of industrializing these processes, thermodynamic properties analyses based on experimental data must be carried out. Actually, thermodynamic information of reacting systems where alkenes and several linear alcohols are involved is scarce. The present study, based on a sound experimental work, contributes to fill part of this lack of information.

\section{EXPERIMENTAL SECTION}

\subsection{Chemicals}

Reactants were methanol (max. water content $0.005 \% \mathrm{wt}$ ), ethanol (max. water content $0.02 \%$ wt.), 1-propanol (max. water content $0.005 \%$ wt.), 1-butanol (max. water content $0.005 \%$ wt.), and either 2-methylpropene (isobutene) or a synthetic $\mathrm{C}_{4}$ mixture as the isobutene source. Some chemical standards were used for analytical procedures: 2-methyl-2-propanol (TBA), diethyl ether (DEE), 2,4,4-trimethyl-1-pentene (TMP-1), 2,4,4-trimethyl-2-pentene (TMP-2), 2ethoxybutane (ESBE), 2-methoxy-2-methylpropane (MTBE), 2-ethoxy-2-methylpropane (ETBE), 2-methyl-2-propoxypropane (PTBE), and 1-tert-butoxybutane (BTBE). The source and purity of all compounds is listed in Table 1.

\section{TABLE 1}

Given that mass spectra for both PTBE and BTBE molecules were not found in the published databases, these mass spectra obtained in our laboratory are provided in the Supporting Information section in Figures S1 and S2, respectively.

\subsection{Catalysts}


Amberlyst ${ }^{\mathrm{TM}} 35$ (A-35, Rohm \& Haas, Chauny, France) was used as catalyst in the majority of the experimental work. Other similar ion exchange resins were tested for comparative purposes: Amberlyst $^{\mathrm{TM}} 15$ (A-15, Rohm \& Haas, Chauny, France), Purolite ${ }^{\circledR}$ CT275 (CT-275, Purolite Ltd., Pontyclun, UK) and Lewatit ${ }^{\circledR}$ K 2620 (K2620, LANXESS AG, Cologne, Germany). All resins were macroreticular, strongly acidic, sulfonated polymers of styrene-divinylbenzene. Relevant properties are listed in Table 2.

\section{TABLE 2}

\subsection{Apparatus and Procedure}

Experiments were carried out at constant temperature in the range $313-383 \mathrm{~K}$ and 1.5-2.0 MPa to keep all components in the liquid phase. Two different reactors were used to carry out the experiments. The first experimental setup consisted of a series of catalytic fixed-bed tubular microreactors (length: $150 \mathrm{~mm}$, i.d.: $7 \mathrm{~mm}$ ). The second setup consisted of a $200 \mathrm{~cm}^{3}$ stainlesssteel jacketed batch reactor. Initial (batch reactor) or fed (tubular reactor) alcohol/isobutene molar ratio $\left(\mathrm{R}_{\mathrm{A} / \mathrm{O}}^{\mathrm{o}}\right)$ ranged from 0.6 to 2.4 .

As catalysts were supplied in wet state, they were pretreated to reduce their water content. Catalysts were firstly dried at room temperature for $48 \mathrm{~h}$ to remove most of the free water from the resin beads and, afterwards, located in an atmospheric oven at $383 \mathrm{~K}$. Catalysts used in the fixed-bed reactor system were then kept in the oven for at least $14 \mathrm{~h}$ until the experiment was carried out. Catalysts used in the batch reactor system were kept in the atmospheric oven for 2.5 $\mathrm{h}$ and, afterwards, placed in a vacuum oven, at $373 \mathrm{~K}$ and $0.001 \mathrm{MPa}$, for $12 \mathrm{~h}$. Final water content in the resin beads after vacuum-drying was 3-5\% wt. (analyzed by Karl-Fischer titration in the laboratory). 
The number of reactor units build in series and the feed flow-rate in the fixed-bed reactor system were chosen for each experiment to achieve a desired liquid hourly space velocity (LHSV) in the range 1.8-20 $\mathrm{h}^{-1}$. Firstly, a weighed amount of oven-dried catalyst was introduced into the designated number of reactors, which were afterwards submerged in a thermostatic bath. Then, only the alcohol was fed to the reactors in order to preheat the catalytic bed and to reduce, as much as possible, the remaining water in the catalyst by alcohol percolation. By means of this procedure, the water content in the resin beads can be reduced to less than $1 \% \mathrm{wt} .{ }^{15}$. Afterwards, while the alcohol flow was kept constant, the pressurized $\mathrm{C}_{4}$ mixture was added to the feed for the reaction to proceed. Then, pressure was fixed at $1.5 \mathrm{MPa}$ in order to ensure all reactants were in the liquid state. From that moment onwards, the composition variation at the outlet stream was monitored by repeated chromatographic analyses. When no significant variation of composition was observed between consecutive analyses, the experiment was ended, since it was considered that the system had reached the steady state.

Regarding the experiments carried out in the batch reactor system, procedure was as follows: the catalyst load, ranging $0.1-10 \%$ wt. of the reactant mixture, was introduced into a catalyst injector and pressurized to 2.0 MPa with nitrogen. The corresponding alcohol was introduced into the reactor vessel before the heating and the stirring $(500-750 \mathrm{rpm})$ were switched on. The isobutene, or the $\mathrm{C}_{4}$ mixture, was first kept in a pressure burette, and then introduced into the reactor by difference of pressures. Once the reactive mixture reached the desired temperature, controlled within $\pm 0.1 \mathrm{~K}$ by a 1,2-propanediol-water thermostatic mixture, the catalyst was injected. This instant was considered as the starting point for the reaction. Experiments lasted 5-8 $\mathrm{h}$, until the reactive medium composition showed no significant variation in time.

\subsection{Analysis}


In the fixed-bed reactor setup, samples were taken inline from the reactor inlet and outlet streams through two sampling valves that injected $0.2 \mu \mathrm{L}$ of pressurized liquid into an Agilent gas chromatograph $7890 \mathrm{~A}$ with a FID detector. In the batch reactor setup, samples were also taken inline from the reaction medium through a sampling valve that injected $0.2 \mu \mathrm{L}$ of pressurized liquid into an Agilent gas chromatograph 6890 with a mass selective detector HP5973N used to identify and quantify the reaction system components. Both GC were equipped with a capillary column HP-PONA 19091S-001 (100\% dimethylpolysiloxane, $50 \mathrm{~m} \times 0.20 \mathrm{~mm} \times$ $0.50 \mu \mathrm{m}$; J\&W Scientific, Santa Clara, CA). The GC oven temperature ranged 308-343 K, the carrier gas flowrate (helium) varied from 0.6 to $1.5 \mathrm{~mL} / \mathrm{min}$, and the analysis duration was $20-45$ min, depending on the considered reaction.

\subsection{Calculations}

For a chemical reaction at a given time, mass-action ratio, $\Gamma_{x}$, corresponds to the ratio of products molar fractions to reactants molar fractions, each raised to the power of the stoichiometric coefficient, $v$. In non-ideal systems, activity coefficients have to be taken into account, as follows:

$$
\Gamma_{a}=\prod_{j=1}^{S} a_{j}^{v_{j}}=\prod_{j=1}^{S} \gamma_{j}^{v_{j}} \cdot \prod_{j=1}^{S} x_{j}^{v_{j}}=\Gamma_{\gamma} \cdot \Gamma_{x}
$$

where $S$ are the species involved in the considered reaction, and $\Gamma_{a}$ and $\Gamma_{\gamma}$ are the mass-action ratios expressed in terms of activities, $a$, and activity coefficients, $\gamma$, respectively. In the present systems, activity coefficients were estimated by means of the modified UNIFAC-Dortmund method ${ }^{16}$.

In a batch stirred tank reactor, chemical equilibrium is reached when the reaction medium composition becomes constant with time. In a fixed-bed reactor, the outlet stream is considered 
to be at chemical equilibrium if its composition at the steady state does not change at decreasing flow rate with the same inlet composition and reaction temperature. When the reaction mixture is at chemical equilibrium, mass-action ratio equals to the equilibrium constant, namely $K_{x}=\Gamma_{x}$, $K_{\gamma}=\Gamma_{\gamma}$, and $K=\Gamma_{a}$, the latest being the thermodynamic equilibrium constant.

\section{RESULTS AND DISCUSSION}

\subsection{Reaction System}

The study was focused on a series of analogous syntheses of alkyl tert-butyl ether from isobutene and $\mathrm{C}_{1}$ to $\mathrm{C}_{4}$ linear primary alcohols. In each part of the experimental work, methanol $(\mathrm{MeOH})$, ethanol $(\mathrm{EtOH})$, 1-propanol (1-PrOH) or 1-butanol $(1-\mathrm{BuOH})$ were used to obtain, respectively, methyl tert-butyl ether (MTBE), ethyl tert-butyl ether (ETBE), propyl tert-butyl ether (PTBE) or butyl tert-butyl ether (BTBE) (reactions R1, R2, R3, and R4, respectively, in Scheme 1).

\section{SCHEME 1}

Possible side-reactions comprise dimerization of isobutene to give TMP-1 and TMP-2, isobutene hydration to give TBA, alcohol dehydration to give water and the corresponding symmetric ether and, as 2-butene is present in the synthetic $\mathrm{C}_{4}$ mixture, the etherification reaction of 2-butene with alcohol to give the corresponding alkyl sec-butyl ether ${ }^{17-19}$. Byproducts formation ranged $0-5.5 \%$ wt. and $0-15.7 \%$ wt. in the fixed-bed and in the batch experiments, respectively. When formed, these byproducts where quantified and, therefore, included in the calculations. Given the extension of some side-reactions in the batch experiments and their irreversible nature, e.g. isobutene dimerization, in some runs a pseudo equilibrium situation was reached rather than a true thermodynamic equilibrium situation. The activities relations corresponding to each equilibrium reaction obtained in such experiments were assumed 
to be equivalent to the equilibrium constant when they were constant in time, within the experimental error.

Regarding the thermodynamic properties, enthalpy, $\Delta_{r} H^{o}$, entropy, $\Delta_{r} S^{o}$, and standard Gibbs free energy, $\Delta_{r} G^{o}$, changes of each reaction at the temperature $\mathrm{T}$, can be estimated from formation properties of the involved compounds by means of the following expressions:

$\Delta_{r} H^{o}(T)=\sum_{j=1}^{S} v_{j} \Delta_{f} H_{j}^{o}$

$\Delta_{r} S^{o}(T)=\sum_{j=1}^{S} v_{j} S_{j}^{o}$

$\Delta_{r} G^{o}(T)=\Delta_{r} H^{o}-T \Delta_{r} S^{o}$

Among thermochemical data concerning these reaction systems, it has been observed: (i) a significant discrepancy in published values for some compounds, or (ii) inexistence of data in the available databases, e.g. BTBE. When available, literature values were compared to experimental results to select the most reliable sources. For non-available values, two different groupcontribution methods (Joback method ${ }^{20}$ and Modified Benson method ${ }^{21-23}$ ) were considered. Estimates obtained by the modified Benson method were found to present lower discrepancies with available published data and, consequently, this method was chosen to estimate the missing values, rather than those obtained by the Joback method. When available, published experimental values were preferred instead of estimates. Values considered in the present work are listed in Table 3.

\section{TABLE 3}

Table 4 lists theoretically estimated values of $\Delta_{r} H^{o}, \Delta_{r} G^{o}$ and $\Delta_{r} S^{o}$ for each alkyl tert-butyl ether synthesis in the liquid phase at $298.15 \mathrm{~K}$, calculated by means of Eqs. 2-4, and the 
corresponding thermodynamic equilibrium constants, $K$, at that temperature according to the following relation:

$\ln K=\frac{-\Delta_{r} G^{o}}{R T}=\frac{-\Delta_{r} H^{o}}{R T}+\frac{\Delta_{r} S^{o}}{R}$

\section{TABLE 4}

To check that the equilibrium constant, $K$, for each reaction was only a function of temperature, that is, to discard possible pressure effects, the Poynting correction factor, $\mathcal{P}$, was calculated by means of the following expression ${ }^{20}$ :

$$
\mathcal{P}=\exp \left(\frac{P-1}{R T} \sum_{j=1}^{S} v_{j} V_{j}\right)
$$

where $V_{j}$ is the liquid molar volume of compound $j$ and $P$ is the pressure expressed in atm. Since values of $\mathcal{P}_{\text {were }}$ close to unity for the whole experimental conditions range, the assumption of null pressure effect on equilibrium constants has been accepted.

\subsection{Experimental Results}

Thermodynamic equilibrium data have been experimentally obtained for the considered series of analogous reactions. The comparison between experimental equilibrium constants, literature values, when available, and theoretical constants from formation data is provided in this section for each synthesis.

\section{MTBE synthesis}

Thermodynamic properties of the MTBE synthesis (reaction R1 in Scheme 1) have been widely studied throughout the years ${ }^{24-30}$. Thus, only few experimental runs were carried out, mainly to compare results with those quoted in literature and to validate the procedure through which equilibrium data were obtained. MTBE experimental data were obtained in the fixed-bed 
reactor system. Experimental conditions and results regarding these runs are provided in the Supporting Information section (Table S1).

Values of the mass-action ratio of chemical compounds activities, $\Gamma_{a}$, were calculated from the fixed-bed reactor outlet stream composition at steady state operating at two temperatures, using different catalysts, and at LHSV values in the range of 2 to $20 \mathrm{~h}^{-1}$. Results depicted in Figure 1 show that, irrespectively of the used catalyst, at LHSV of about $2 \mathrm{~h}^{-1}$ the calculated $\Gamma_{a}$ values can be considered equal to the thermodynamic equilibrium constant values, $K_{M T B E}$, quoted in literature ${ }^{24-30}$, within the margin of experimental error, for both temperatures. For higher LHSV, $\Gamma_{a}$ decreases at increasing LHSV, and reactor outlet stream would not be at equilibrium. In particular, under the same LHSV and temperature conditions, the calculated value of $\Gamma_{a}$ is larger when the used catalyst has a higher acid capacity, as a result of its higher catalytic activity.

\section{FIGURE 1}

Figure 2 provides a comparison between experimental $K_{M T B E}$ at 323 and $343 \mathrm{~K}$, those quoted in literature, and theoretically determined equilibrium constants at different temperatures. The agreement between results proves that the followed procedure to obtain equilibrium constants is reliable.

FIGURE 2

\section{ETBE synthesis}

Even though thermodynamics of the ETBE synthesis (reaction R2 in Scheme 1) has been also extensively dealt with in literature, for instance ${ }^{31-36}$, the lack of agreement between sources has often led to a discrepancy between theoretically and experimentally obtained equilibrium constants ${ }^{36}$. Thus, part of this study has been devoted to this reaction. In order to confirm the reliability of the experimental equilibrium obtained in this work, ETBE experiments were carried 
out in two different reactor systems, in a wider temperature range (313-383 K) and using different catalysts. Experimental conditions and results for each individual experiment are provided in the Supporting Information section (Tables S2 and S3).

As example, results of some experimental runs in each setup are shown in Figure 3. Figure 3A, where a batch experiment performed at $323 \mathrm{~K}, \mathrm{R}_{\mathrm{A} / \mathrm{O}}^{\mathrm{o}}=0.64$, and $10 \% \mathrm{wt}$ of $\mathrm{A}-35$ as catalyst load is shown, depicts the evolution in time of each compound molar fraction, $x$. Given that the catalyst load was high, isobutene and ethanol quickly reacted to give ETBE, which reached a molar fraction that hardly evolved in time, within the margin of experimental error. Concentration of $\mathrm{C}_{4}$ compounds other than isobutene barely changed during the experiment, because isobutane is an inert compound under the reaction conditions, and 2-butene needs higher temperatures and ethanol initial concentrations to react in a significant extension. Regarding side-reactions, TMP-1 and TMP-2 were the more largely formed byproducts.

Figure 3B shows the variation with LHSV of the reactor outlet stream composition, in terms of $x_{i}$, for fixed-bed experiments at $333 \mathrm{~K}, \mathrm{R}_{\mathrm{A} / \mathrm{O}}^{\mathrm{o}}=1.10$, and using $\mathrm{A}-35$ as catalyst. As seen in the figure, no significant variations were detected for different LHSV, what means that ETBE kinetics was fast enough to reach chemical equilibrium at the reactor outlet in all the experimental conditions range.

\section{FIGURE 3}

Regarding the equilibrium constant values for the ETBE synthesis, the comparison between experimental results, those quoted in the literature and theoretical estimated values is provided in Figure 4. As seen, experimental equilibrium constants, $K_{E T B E}$, are in a relatively good agreement with both literature and theoretical values. It is noticeable that linear fits applied to experimental results and to $K_{\text {ETBE }}$ values derived from the expressions suggested by Jensen and Datta ${ }^{33}$ almost 
coincide in slopes and only a slight discrepancy in intercepts is observed. This fact, adds reliability to the experimental results presented in the present work.

\section{FIGURE 4}

\section{PTBE synthesis}

Studies of thermodynamic properties on the PTBE synthesis (reaction R3 in Scheme 1) are scarce in literature; only few works that studied this reaction were found ${ }^{37-40}$. Experiments have been carried out in the batch stirred tank reactor from different initial alcohol/isobutene molar ratio, $\mathrm{R}_{\mathrm{A} / \mathrm{O}}^{\mathrm{O}}$, and at different temperatures, using $\mathrm{A}-35$ as the catalyst. Figure 5 shows the evolution in time of the PTBE molar fraction until chemical equilibrium was reached in the different experimental runs. Experimental results at chemical equilibrium are given in Table 5.

\section{FIGURE 5}

\section{TABLE 5}

Figure 6 provides a comparison between experimental, published ${ }^{37}$, and theoretically estimated values of $K_{P T B E}$. Although in that figure some discrepancies are revealed, the slope of the linear fit of the theoretically determined equilibrium constants and that of the present work are almost coincident. Regarding values quoted in literature, the trend they describe differs from that described by both experimental $K_{P T B E}$ of the present work and theoretical values.

\section{FIGURE 6}

\section{BTBE synthesis}

Studies concerning BTBE synthesis (reaction R4 in Scheme 1) equilibrium are hard to find in literature ${ }^{42,43}$. To estimate thermodynamic properties, we followed the same procedure in which temperature and initial concentrations were varied to reach equilibrium compositions, using A-35 as the catalyst in the batch reactor. Figure 7 shows the evolution in time of the BTBE molar 
fraction for the different experimental runs until chemical equilibrium was reached. Experimental results at equilibrium are given in Table 6.

\section{FIGURE 7}

\section{TABLE 6}

In Figure 8, experimental $\mathrm{K}_{\mathrm{BTBE}}$ values are compared to those reported in literature and to theoretically determined ones. As it can be seen, experimental data from literature ${ }^{42}$ and from the present work are coincident, whereas a significant discrepancy can be observed regarding theoretical equilibrium constants. From dashed lines in Figure 8, it becomes clear that discrepancies between theoretically estimated and experimental values involve intercepts rather than slopes of linear fits.

\section{FIGURE 8}

\subsection{Thermodynamic Properties}

Figure 9 depicts $\ln K$ versus $1 / T$ for the four studied equilibrium reactions, by assuming that the enthalpy change of etherification reactions can be considered constant within the assayed temperature range. As seen in the figure, experimental results fit well to straight lines and therefore reaction enthalpy could be considered independent on temperature $\left(\Delta_{r} H^{o} \neq f(\mathrm{~T})\right)$.

\section{FIGURE 9}

The standard molar enthalpy change of reaction, $\Delta_{r} H^{o}$, can be obtained from the slope and the standard molar entropy change of reaction, $\Delta_{r} S^{o}$, from the intercept. The resulting fitted equations obtained by least squares regression are, the uncertainty of the parameters being at the 95 percent level of confidence (coverage factor for parameters in $K_{M T B E}$ and $K_{B T B E}: 2.57 ; K_{E T B E}$ :

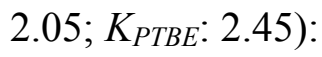

$\ln K_{M T B E}=\frac{(4540 \pm 1190)}{T}-(9.7 \pm 3.5)$ 


$$
\begin{aligned}
& \ln K_{E T B E}=\frac{(4860 \pm 210)}{T}-(11.46 \pm 0.60) \\
& \ln K_{P T B E}=\frac{(4360 \pm 430)}{T}-(9.52 \pm 1.29) \\
& \ln K_{B T B E}=\frac{(4570 \pm 340)}{T}-(10.30 \pm 0.99)
\end{aligned}
$$

Eq. 7 is shown for comparative purposes, since it presents a considerable uncertainty in its parameters because MTBE experiments were performed at only two temperatures. Thus, the above expression is not recommended to determine thermodynamic properties of the MTBE synthesis. The following expression from literature ${ }^{26}$ should be used instead.

$$
\ln K_{M T B E}=\frac{(4703 \pm 96)}{T}-(10.3 \pm 0.1)
$$

On the other hand, if $\Delta_{r} H^{o}$ is considered to be temperature dependent, it can be expressed by the Kirchoff equation:

$\frac{d \Delta_{r} H^{o}}{d T}=\sum_{j=1}^{S} v_{j} C_{P_{j}}^{o}$

where $C_{P_{j}}^{o}$ is the liquid phase molar heat capacity of each compound $j$ in the considered reaction, which can be calculated as a function of the temperature by the equation and coefficients given in Table 7.

\section{TABLE 7}

Table 7 shows heat capacity coefficients taken from literature, estimated and experimentally determined. Literature values from different sources are reliable beyond doubt. As example, ETBE-related values from different works ${ }^{27,33,36}$ lead to the same estimated heat capacity. With respect to unavailable coefficients, estimation of 1-propanol and 1-butanol molar heat capacities by different estimation methods, i.e. Missenard and Růžička-Domalski methods ${ }^{20,21}$, lead to 
values that are similar to those quoted in literature ${ }^{44}$ and consequently they can be considered as reliable. Missenard estimates were chosen because overall discrepancies with available databases regarding the four studied alcohols were found to be lower. As for the two missing ethers, namely PTBE and BTBE, their molar heat capacity variation with temperature was experimentally determined at the Scientific and Technological Centers (CCiT) of the University of Barcelona by differential scanning calorimetry (DSC) analysis in the temperature range of 298 to $368 \mathrm{~K}$, which allowed obtaining the coefficients by fitting the equation in Table 7. Figure 10 shows the molar heat capacity values that were not found in the available literature as a function of temperature.

FIGURE 10

The integrated form of the Kirchoff equation, combined with the equation in Table 7, gives the following expression for each reaction:

$$
\Delta_{r} H^{o}=I_{K}+a T+\frac{b}{2} T^{2}+\frac{c}{3} T^{3}+\frac{d}{4} T^{4}
$$

where:

$$
a=\sum_{j=l}^{S} v_{j} a_{j} \quad b=\sum_{j=l}^{S} v_{j} b_{j} \quad c=\sum_{j=l}^{S} v_{j} c_{j} \quad d=\sum_{j=l}^{S} v_{j} d_{j}
$$

The dependence of the equilibrium constant on temperature is described by the van't Hoff equation:

$$
\frac{d \ln K}{d T}=\frac{-\Delta_{r} H^{o}}{R T^{2}}
$$

Eq. 15, combined with Eq. 13 and integrated, leads to:

$$
\ln K=I_{H}-\frac{I_{K}}{R T}+\frac{a}{R} \ln T+\frac{b}{2 R} T+\frac{c}{6 R} T^{2}+\frac{d}{12 R} T^{3}
$$


where $I_{K}$ and $I_{H}$ are the integration constants. The fit of Eq. 16 to the experimental values of the equilibrium constants at different temperatures allows obtaining $I_{K}$ value from the slope and $I_{H}$ value from the intercept. Figure 11 provides the Van't Hoff plot when reaction enthalpy change is considered temperature dependent $\left(\Delta_{r} H^{o}=f(\mathrm{~T})\right)$.

\section{FIGURE 11}

Finally, the standard molar entropy and free energy changes of each reaction, $\Delta_{r} S^{o}$ and $\Delta_{r} G^{o}$, can be evaluated by means of the following expressions:

$$
\begin{aligned}
& \Delta S^{o}=R I_{H}+a+a \ln T+b T+\frac{c}{2} T^{2}+\frac{d}{3} T^{3} \\
& \Delta G^{o}=I_{K}-R I_{H} T-a T \ln T-\frac{b}{2} T^{2}-\frac{c}{6} T^{3}-\frac{d}{12} T^{4}
\end{aligned}
$$

Parameters of Eqs. 13, 16-18 are shown in Table 8. Summary of thermochemical properties determined for the studied reactions is provided in Table 9.

\section{TABLE 8}

\section{TABLE 9}

The estimated values of the thermodynamic properties of the studied reactions are globally in good agreement with the data available in the literature (Table 9). In this work, values for MTBE synthesis have been obtained from experimental runs at only two temperatures, with a large relative uncertainty, and, therefore, they are provided for comparative purposes. Consequently, the use of literature values for MTBE is recommended, especially those by Izquierdo et al ${ }^{26}$. Concerning ETBE synthesis, the estimated values are coincident, within the experimental error, with those reported by Jensen and Datta ${ }^{33}$, obtained from both theoretical relations and experimental results, and with those by Soto et al ${ }^{36}$, determined experimentally in a slightly different reaction system, the simultaneous production of ETBE and tert-amyl ethyl ether. Values by Françoisse and Thyrion ${ }^{31}$ are a bit larger, and values by Sharonov et al ${ }^{34}$ agree with 
theoretical values. There are very few studies in the available literature devoted to thermodynamic equilibrium of PTBE and BTBE synthesis. In the PTBE synthesis, the estimated values are close to the theoretical ones, and differences with Linnekoski et al ${ }^{37}$ are regarded as inconclusive. With respect to BTBE synthesis, the present results agree with the values reported by Sharonov et al ${ }^{42}$, and they are close to the theoretical ones.

A rather good agreement is observed between experimental and theoretically estimated thermodynamic state functions. Nevertheless, slight differences between theoretical and experimental thermodynamic properties lead to obvious discrepancies regarding theoretical and experimentally obtained equilibrium constants, as it has been already commented, given the exponential dependence defined by the Van't Hoff equation. These discrepancies are particularly evident in the intercepts of the Van't Hoff plots rather than in their slopes. Consequently, discrepancies between theoretical and experimental entropy changes of reaction are larger than between enthalpy changes. As example, the theoretical entropy change of the ETBE synthesis seems to be overestimated, as it can be seen by comparing that value to those reported either in this work or in literature. In this sense, a remark should be made about the thermochemical data used to determine theoretical values: experimentally-based databases should be extended because, even though estimation methods can provide relatively accurate values, small deviations lead to considerable discrepancies with experimental thermodynamic data.

At this point, thermochemical data of formation of the four ethers produced in these reactions have been readjusted accordingly with present experimental data, by considering the reaction enthalpy as a function of temperature $\left(\Delta_{r} H^{o}=f(\mathrm{~T})\right)$. As seen in Table 10, relative differences of readjusted values, compared to those presented in Table 3, are quite low and, therefore, they can 
be considered as acceptable. The general agreement between proposed values and either reported or estimated ones reinforces the reliability of the present study.

\section{TABLE 10}

Finally, concerning the two alternatives early used on whether to consider the reaction enthalpy change as a function of temperature or not $\left(\Delta_{r} H^{o}=f(\mathrm{~T})\right.$ or $\left.\Delta_{r} H_{i}^{o} \neq f(\mathrm{~T})\right)$, Table 11 shows the variation of the enthalpy change of reaction, $\Delta_{r} H^{o}$, in the temperature range $323-353 \mathrm{~K}$. As seen in the table, maximum relative differences between values are $2.7 \%, 3.6 \%, 7.1 \%$, and $7.6 \%$, for the syntheses of MTBE, ETBE, PTBE, and BTBE, respectively. Thus, enthalpies of reaction are more sensitive to temperature variations as the size of the produced ether increases, especially for PTBE and BTBE.

\section{TABLE 11}

The variation with temperature of enthalpy changes of reaction regarding the four studied syntheses are quite close to those previously reported in literature. For instance, observed enthalpy variations in the syntheses of MTBE and ETBE were 3.4\% and 3.6\%, respectively, over the same temperature range, according to values previously reported ${ }^{26,36}$. On the other hand, also from literature values ${ }^{37,42}$, the variation with temperature of PTBE and BTBE enthalpy changes of reaction were $10 \%$ and $9 \%$, respectively, over the same temperature range. Therefore, regarding both PTBE and BTBE syntheses, it would be advisable to consider the enthalpy change of reaction as temperature dependent.

\section{CONCLUSIONS}

Extensive experimental data are provided to estimate enthalpy, entropy and free energy changes of liquid-phase etherification of isobutene with $\mathrm{C}_{1}$ to $\mathrm{C}_{4}$ linear primary alcohols. Experimental equilibrium results for the involved reactions have been proven to be independent 
of the catalyst and reactor type. All four chemical reactions have been found to be reversible and exothermic. Consequently, the amount of produced ethers at equilibrium decreases at increasing temperature.

If the enthalpy change of reaction is considered as independent on temperature, estimated values of the liquid-phase standard enthalpy changes of the synthesis reactions of MTBE, ETBE, PTBE and BTBE are $-38 \pm 10,-40.4 \pm 1.7,-36 \pm 4$, and $-38 \pm 3 \mathrm{~kJ} \mathrm{~mol}^{-1}$, respectively. If the enthalpy change is considered as a function of temperature, their estimated values at $298.15 \mathrm{~K}$ are $-37 \pm 10,-38.5 \pm 1.7,-34 \pm 3$ and $-35 \pm 3 \mathrm{~kJ} \mathrm{~mol}^{-1}$, respectively. Reaction enthalpies of PTBE and BTBE synthesis are more sensitive to temperature than those of MTBE and ETBE synthesis.

Liquid-phase standard state thermochemical data concerning the four produced ethers have been estimated as the following enthalpies of formation: $-313.5,-353.6,-373.6$ and $-399.8 \mathrm{~kJ}$ $\mathrm{mol}^{-1}$, and the following entropies: 264.5, 286.7, 338.5 and $365.0 \mathrm{~J}(\mathrm{~mol} \mathrm{~K})^{-1}$ for MTBE, ETBE, PTBE and BTBE, respectively. 


\section{FIGURES}

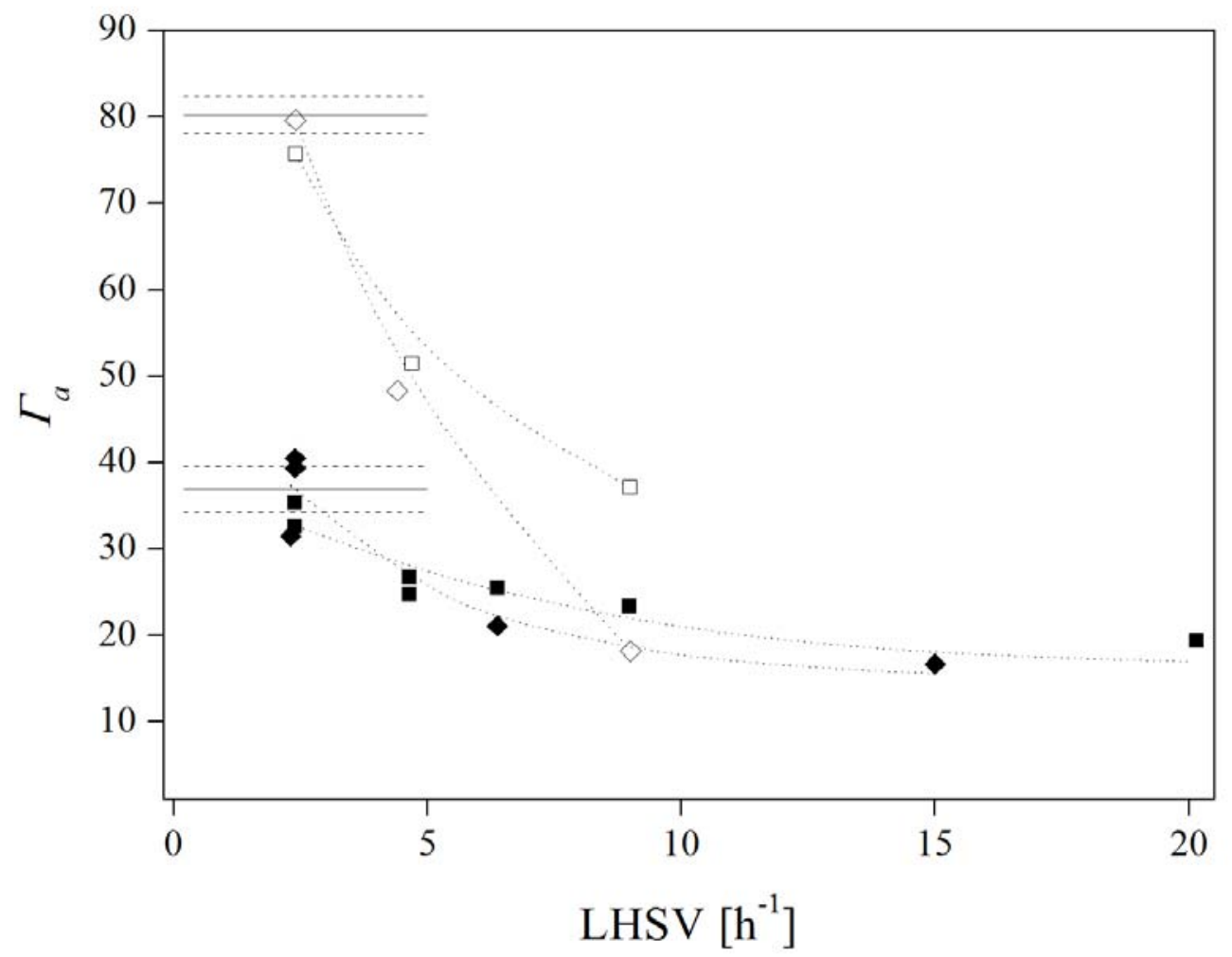

"Figure 1. Experimental mass-action ratio, $\Gamma_{a}$, dependence on LHSV for the MTBE experiments. Mean literature values ${ }^{24-30}$ of the MTBE thermodynamic equilibrium constant, $K_{M T B E}$, at each temperature are represented with solid lines, and their respective standard uncertainty margin is represented with dashed lines. Open symbols $(\mathrm{T}=323 \mathrm{~K})$ : A-15 $(\diamond)$, A-35

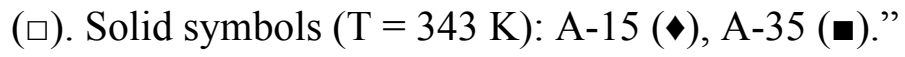




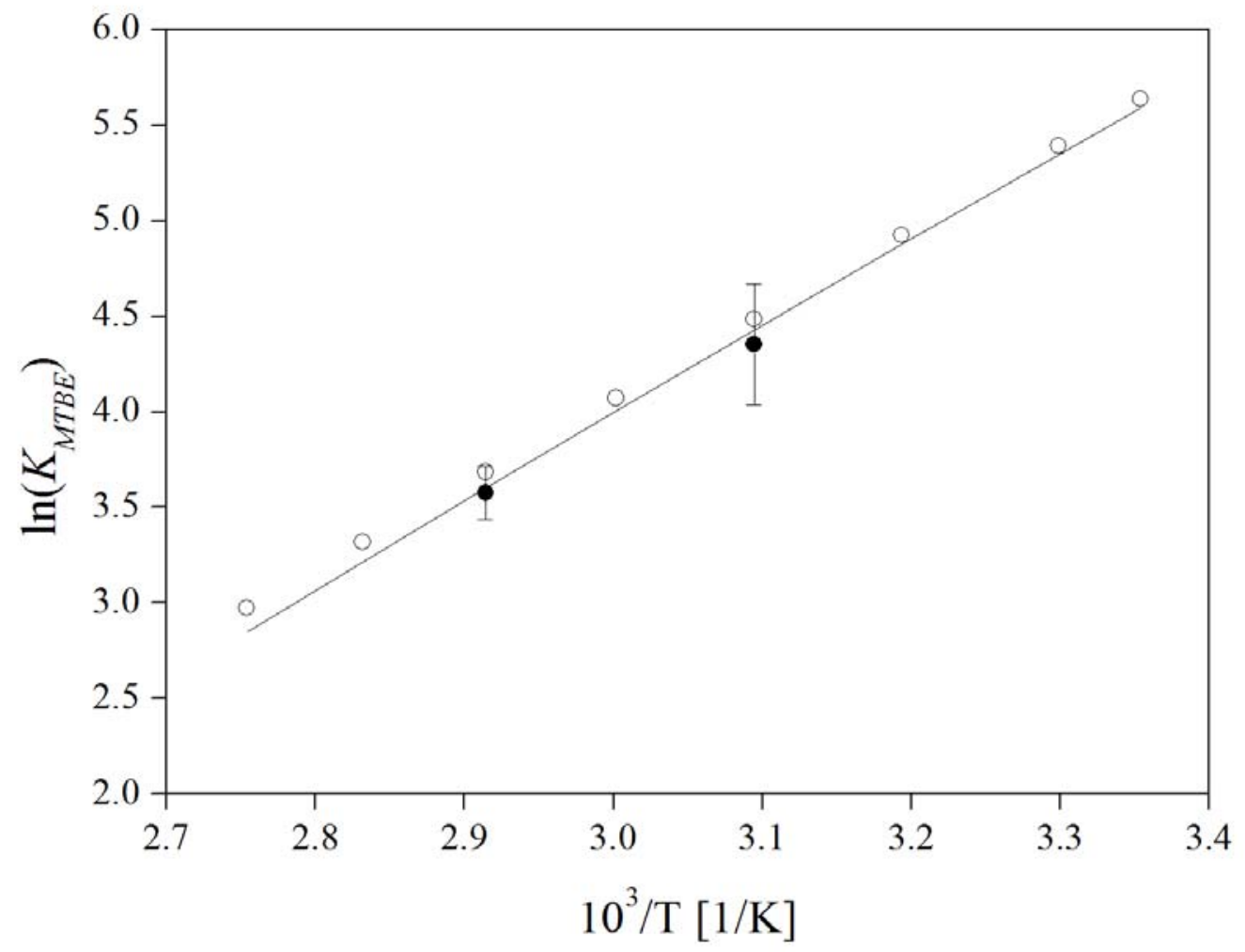

"Figure 2. Comparison between MTBE equilibrium constant values. Error bars correspond to expanded uncertainty for 95 percent level of confidence (coverage factors: 12.71 at $323 \mathrm{~K} ; 2.78$ at $343 \mathrm{~K})$. Present work $(\bullet)$, theoretically determined values $(\circ)$, and linear fit of literature values ${ }^{24-30}(-) . "$ 

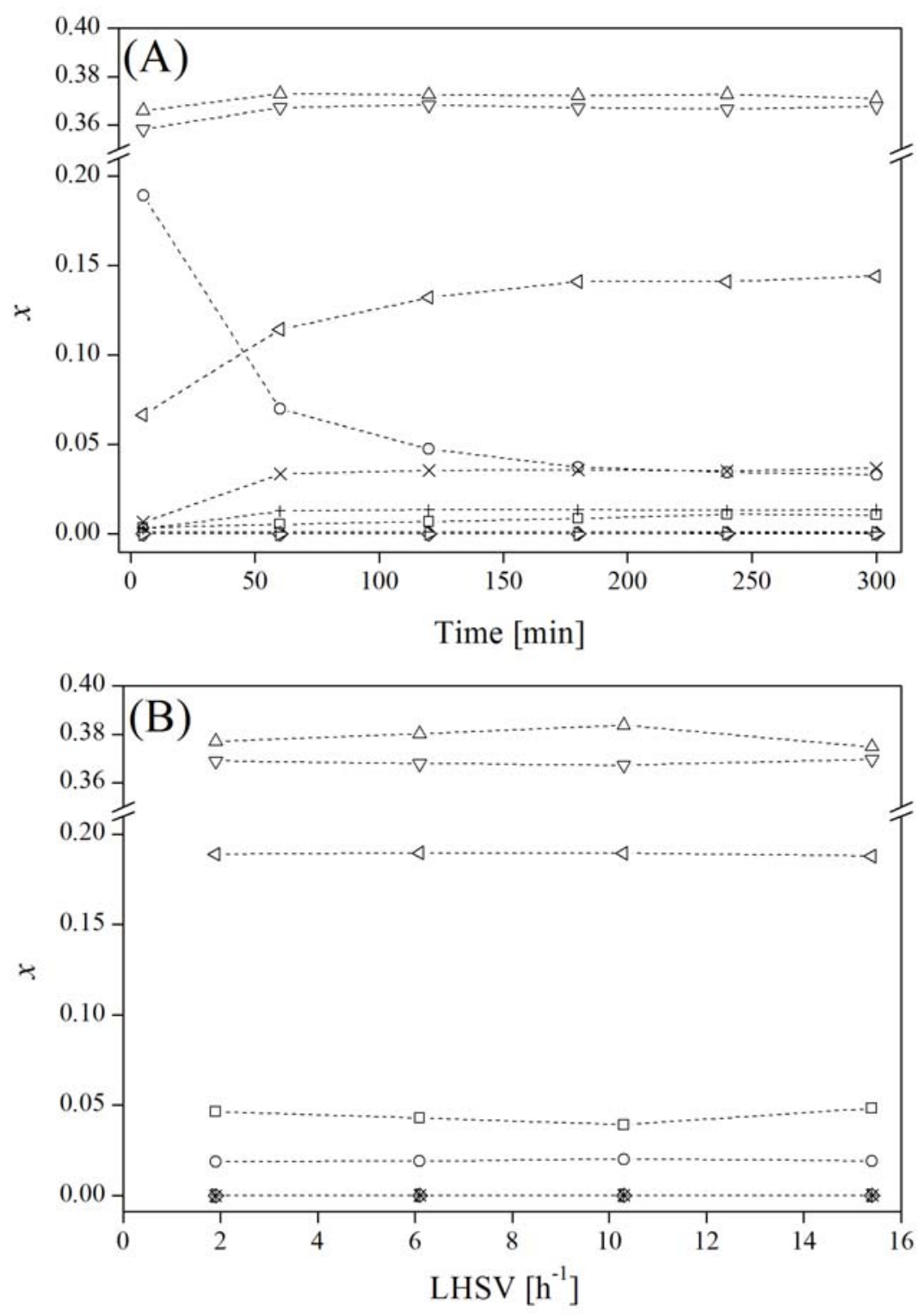

"Figure 3. Molar fraction evolution in time for the ETBE synthesis in a batch experiment at $\mathrm{T}=323 \mathrm{~K}, \mathrm{R}_{\mathrm{A} / \mathrm{O}}^{\mathrm{o}}=0.64$, stirring speed of $500 \mathrm{rpm}$, with a catalyst load of A-35 equal to $10 \% \mathrm{wt}$. of the reactant mixture (A), and outlet stream steady-state molar fraction variation with LHSV for the ETBE synthesis in fixed-bed experiments at $\mathrm{T}=333 \mathrm{~K}, \mathrm{R}_{\mathrm{A} / \mathrm{O}}^{\mathrm{o}}=1.10$, using A-35 as catalyst (B). $\mathrm{IB}(\circ), \operatorname{EtOH}(\square)$, isobutane $(\Delta), 2$-butene $(\nabla), \operatorname{ETBE}(\triangleleft), \operatorname{ESBE}(\triangleright), \operatorname{DEE}(\diamond), \operatorname{TBA}(-)$, TMP-1 (×) and TMP-2 (+).” 


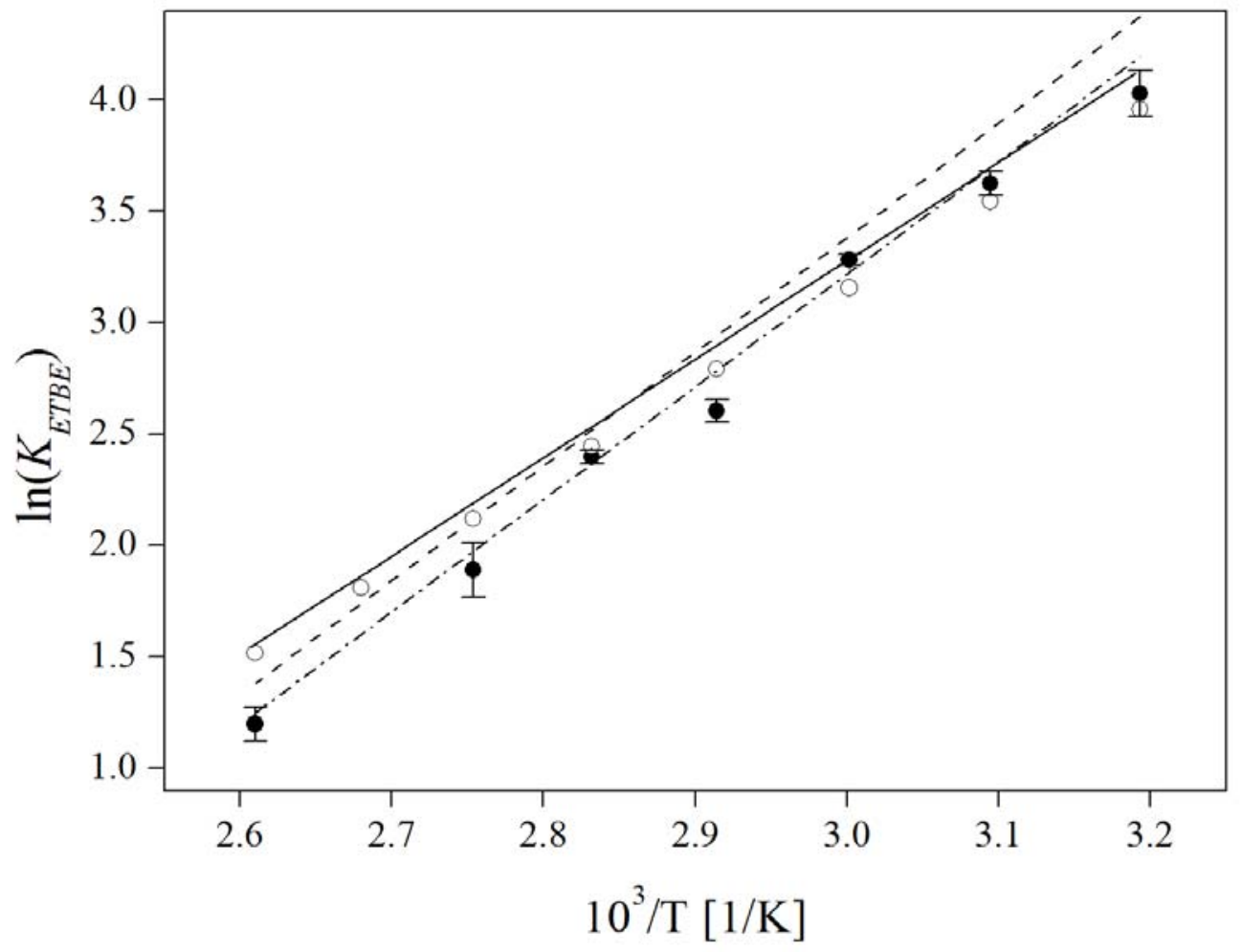

"Figure 4. Comparison between values for ETBE equilibrium constants. Error bars correspond to expanded uncertainty for 95 percent level of confidence (coverage factors: 4.30 at 313-333 K; 2.78 at $343 \mathrm{~K}$ and $383 \mathrm{~K} ; 2.57$ at $353 \mathrm{~K} ; 3.18$ at $363 \mathrm{~K}$ ). Present work (•), theoretically determined (०), linear fit of literature values ${ }^{31-36}\left({ }^{-}\right)$, linear fit applied to Jensen and Datta ${ }^{33}$ expressions values (-- ), and linear fit applied to present work values $(\cdot-\cdot-\cdot), "$ 


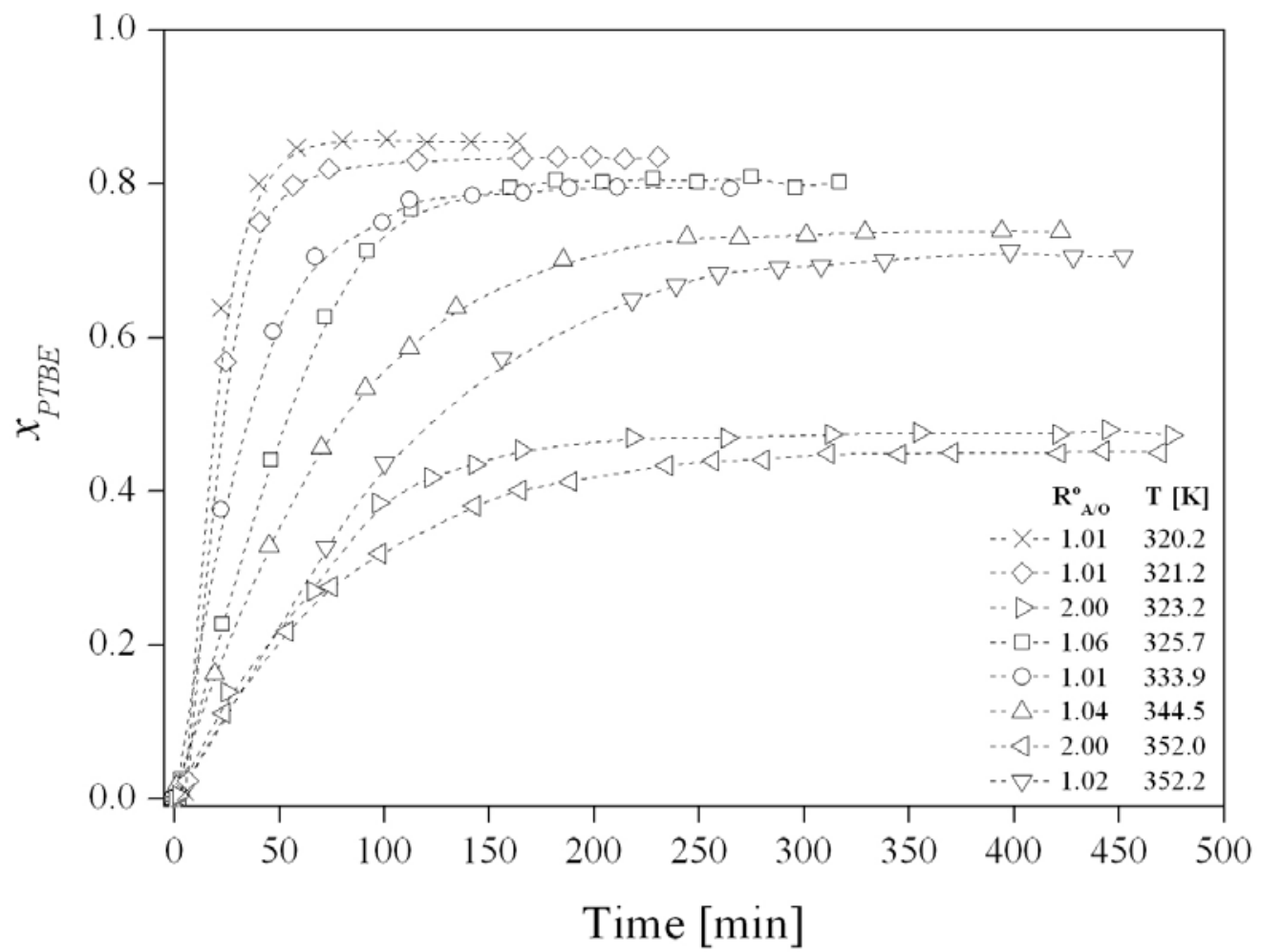

"Figure 5. Evolution in time of PTBE molar fraction in batch experiments at different $\mathrm{R}_{\mathrm{A} / \mathrm{O}}^{\mathrm{O}}$ and temperatures. A-35, catalyst load $=0.1-11 \%$ wt., 750 rpm.” 


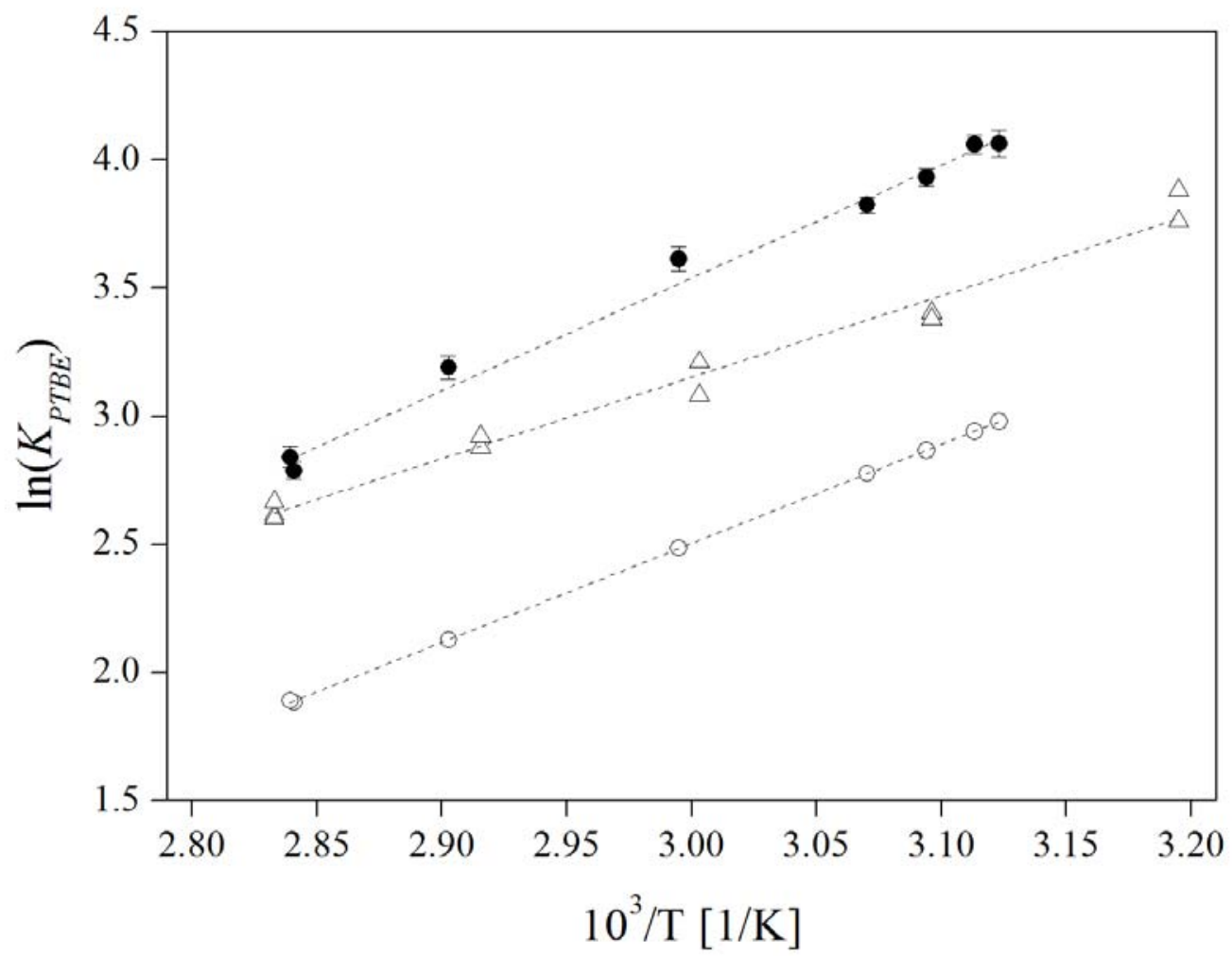

"Figure 6. Comparison between values for PTBE equilibrium constant. Error bars correspond to expanded uncertainty for 95 percent level of confidence (coverage factor: 1.96). Present work $(\bullet)$, literature values ${ }^{37}(\Delta)$, and theoretically estimated values $(\circ) .$, 


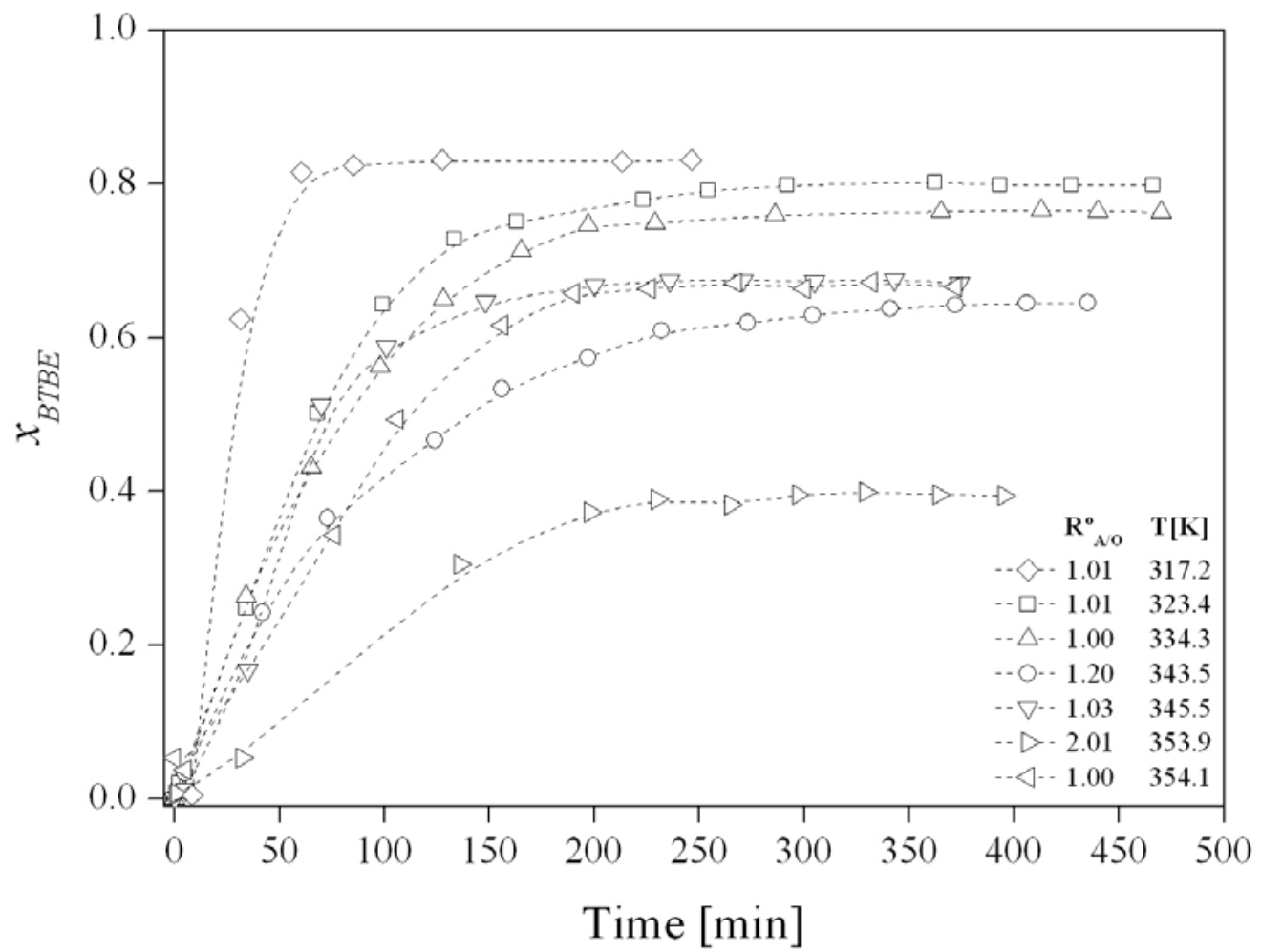

"Figure 7. Evolution in time of BTBE molar fraction in batch experiments at different $\mathrm{R}_{\mathrm{A} / \mathrm{O}}^{\mathrm{O}}$ and temperatures. A-35, catalyst load $=0.1-7 \%$ wt., 750 rpm.” 


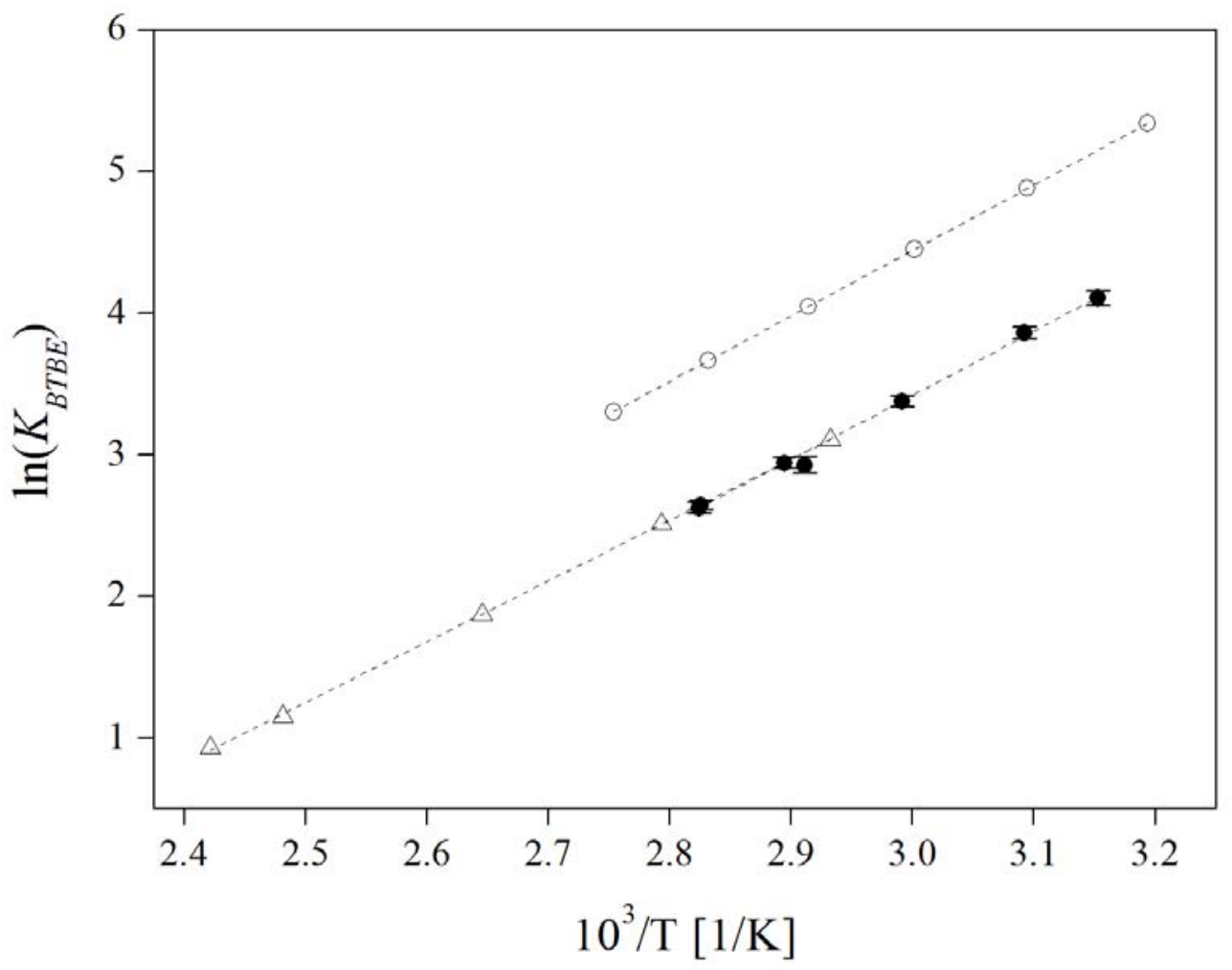

"Figure 8. Comparison between values for BTBE equilibrium constant. Error bars correspond to expanded uncertainty for 95 percent level of confidence (coverage factor: 1.96). Present work $(\bullet)$, literature values ${ }^{42}(\Delta)$, and theoretically estimated values $(\circ) . ”$ 


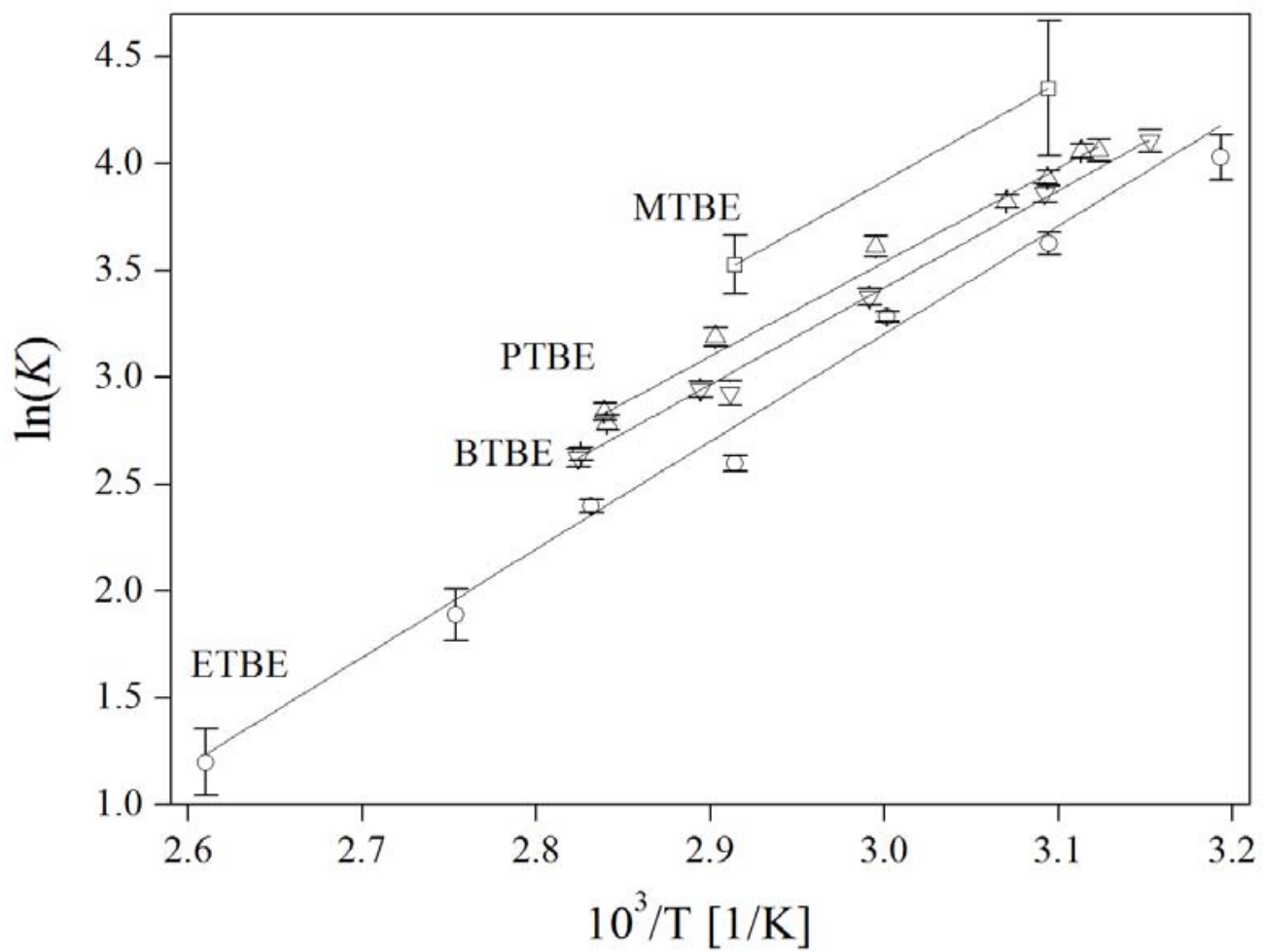

"Figure 9. Van't Hoff plot when considering reaction enthalpy change constant within the temperature range $\left(\Delta_{r} H^{o} \neq f(\mathrm{~T})\right)$. Error bars correspond to expanded uncertainty for 95 percent level of confidence (coverage factors: as indicated in Fig. 2, 4, 6, and 8). Solid lines refer to the values predicted using Eqs. 7-10." 


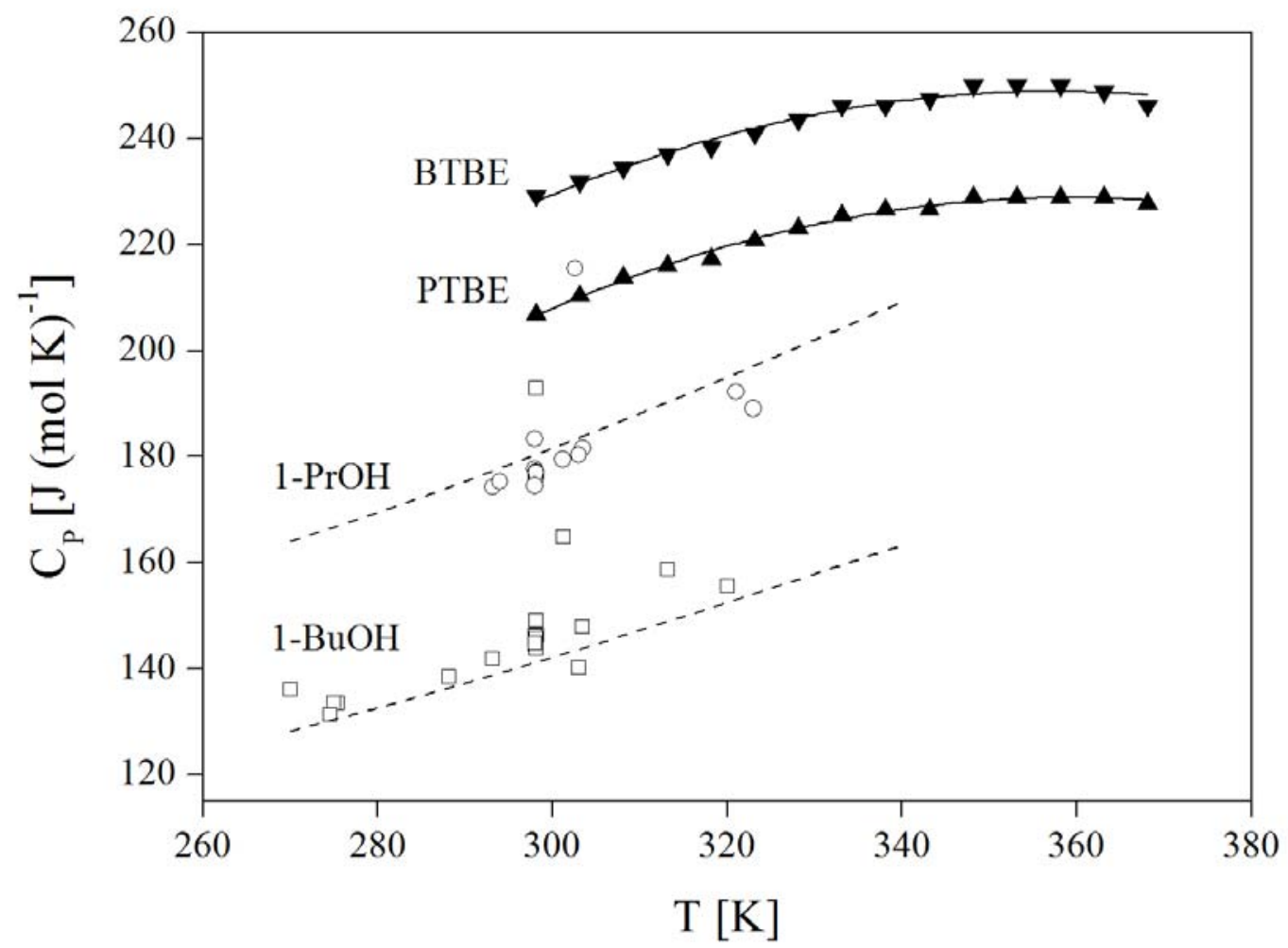

"Figure 10. Molar heat capacity variation with temperature. Solid lines correspond to predicted values using the equation and parameters in Table 7. Dashed lines correspond to estimation of molar heat capacity by Missenard method. Solid symbols refer to experimental determination by DSC: PTBE ( $\boldsymbol{\Delta})$, BTBE $(\boldsymbol{\nabla})$. Open symbols refer to literature values ${ }^{44}$ : 1-propanol (०), 1-butanol (口).” 


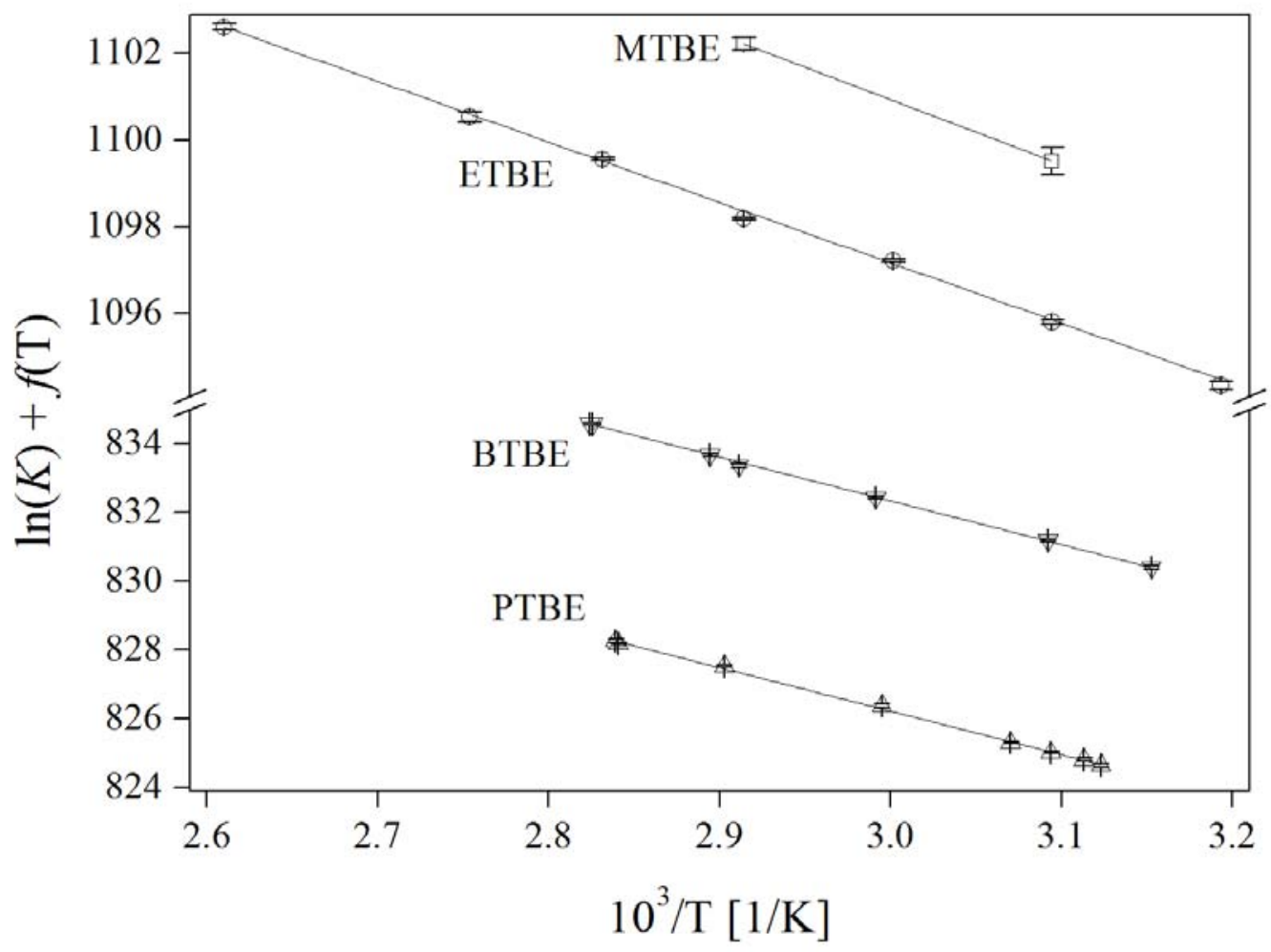

"Figure 11. Van't Hoff plot when considering reaction enthalpy as a function of temperature $\left(\Delta_{r} H^{o}=f(\mathrm{~T})\right)$. Error bars correspond to expanded uncertainty for 95 percent level of confidence (coverage factors: as indicated in Fig. 2, 4, 6, and 8). Solid lines refer to the values predicted by Eq. 15 for each reaction with parameters in Table 8." 


\section{SCHEMES}

"Scheme 1. Main reactions involved."<smiles>C=C(C)CC</smiles>

IB<smiles>C=C(C)C</smiles>

IB<smiles>C=C(C)C</smiles>

IB<smiles>C=C(C)C</smiles>

IB
$+$<smiles>O</smiles>

$\mathrm{MeOH}$

$+$<smiles>CCO</smiles>

EtOH<smiles>CCCO</smiles>

1-PrOH
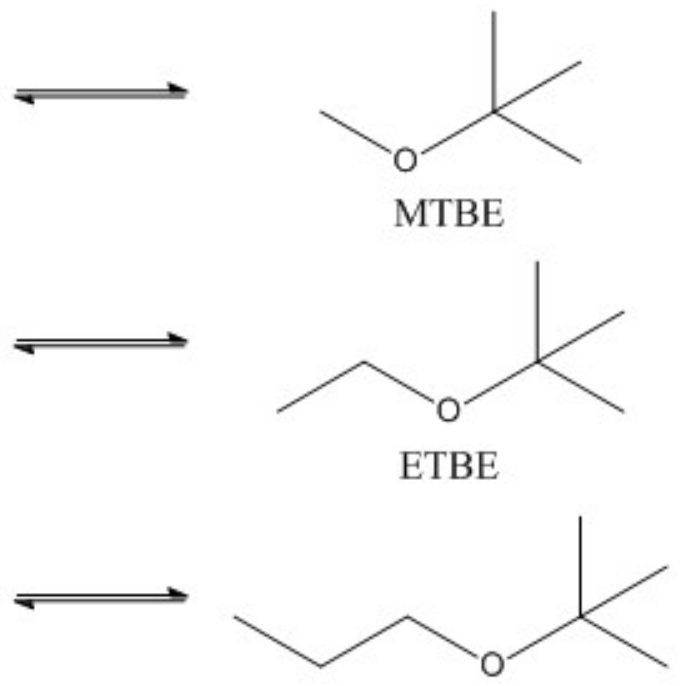<smiles>CCCCO</smiles><smiles>C=CCCCOC(C)(C)C</smiles>

MTBE

ETBE

PTBE

R4

R1

R2

R3

BTBE 
TABLES.

"Table 1. Source, purity, and analysis of used materials."

\begin{tabular}{|c|c|c|c|}
\hline Compound & Source & $\begin{array}{l}\text { Mass } \\
\text { Fraction } \\
\text { Purity }\end{array}$ & Analysis Method \\
\hline methanol & Panreac & $\geq 99.8$ & gas chromatography \\
\hline ethanol & Panreac & $\geq 99.8$ & gas chromatography \\
\hline 1-propanol & Sigma-Aldrich & $\geq 99.7$ & gas chromatography \\
\hline 1-butanol & Sigma-Aldrich & $\geq 99.8$ & gas chromatography \\
\hline 2-methylpropene & Air Liquide & $\geq 99.9$ & gas chromatography \\
\hline $\mathrm{C}_{4}$ mixture $^{\mathrm{a}}$ & Abelló-Linde & $\geq 99.9$ & gas chromatography \\
\hline 2-methyl-2-propanol & Panreac & $\geq 99.7$ & gas chromatography \\
\hline diethyl ether & Panreac & $\geq 99.5$ & gas chromatography \\
\hline 2,4,4-trimethyl-1-pentene & Sigma-Aldrich & $\geq 98.0$ & gas chromatography \\
\hline 2,4,4-trimethyl-2-pentene & Sigma-Aldrich & $\geq 98.0$ & gas chromatography \\
\hline 2-ethoxybutane & TCI Europe & $\geq 99.7$ & gas chromatography \\
\hline 2-methoxy-2-methylpropane & Panreac & $\geq 99.9$ & gas chromatography \\
\hline 2-ethoxy-2-methylpropane & TCI Europe & $\geq 95.0$ & gas chromatography \\
\hline 2-methyl-2-propoxypropane & synthesis & $\geq 99.0^{b}$ & gas chromatography \\
\hline 1-tert-butoxybutane & synthesis & $\geq 98.0^{\mathrm{b}}$ & gas chromatography \\
\hline nitrogen & Air Liquide & $\geq 99.9995$ & - \\
\hline helium & Abelló-Linde & $\geq 99.998$ & - \\
\hline
\end{tabular}

${ }^{\mathrm{a}} \mathrm{C}_{4}$ mixture composition: $25 \%$ wt. 2-methylpropene, $40 \% \mathrm{wt}$. isobutane, and $35 \%$ trans-2butene. ${ }^{\mathrm{b}}$ Purified in our lab through liquid-liquid extraction followed by rectification. 
“Table 2. Physical properties of assayed catalysts, with expanded uncertainties for 95 percent level of confidence (coverage factor: 3.18)."

\begin{tabular}{|c|c|c|c|c|c|}
\hline Catalyst & Short name & $\begin{array}{l}\text { Acid Capacity }^{\mathrm{a}} \\
{\left[\text { meq } \mathrm{H}^{+} / \mathrm{g}_{\text {cat }}\right]}\end{array}$ & $\begin{array}{c}\mathrm{S}_{\mathrm{g}}^{\mathrm{b}} \\
{\left[\mathrm{m}^{2} / \mathrm{g}_{\text {cat }}\right]}\end{array}$ & $\begin{array}{l}\mathrm{d}_{\mathrm{p}, \mathrm{m}}{ }^{\mathrm{c}} \\
{[\mu \mathrm{m}]}\end{array}$ & $\begin{array}{l}\mathrm{T}_{\max } \\
{[\mathrm{K}]}\end{array}$ \\
\hline Amberlyst 35 & A-35 & $5.32 \pm 0.06$ & $28.9 \pm 0.5$ & $623 \pm 3$ & 423 \\
\hline Purolite CT275 & CT-275 & $5.30 \pm 0.10$ & $20.3 \pm 0.3$ & $746 \pm 3$ & 418 \\
\hline Amberlyst 15 & A-15 & $4.81 \pm 0.04$ & $42.0 \pm 0.2$ & $740 \pm 3$ & 393 \\
\hline Lewatit K 2620 & K2620 & $5.07 \pm 0.05$ & $28.7 \pm 0.4$ & $620 \pm 3$ & 413 \\
\hline
\end{tabular}

${ }^{\mathrm{a}}$ Modified Fisher-Kunin titration against standard base ${ }^{45} \cdot{ }^{\mathrm{b}}$ BET Method. ${ }^{\mathrm{c}}$ Mean particle diameter from laser diffraction in air. 
"Table 3. Thermochemical data of the involved chemical species (standard state, liquid at 1 atm and $298.15 \mathrm{~K}) . "$

\begin{tabular}{lcc}
\hline Compound & $\begin{array}{c}\Delta_{f} H^{\mathrm{o}} \\
{\left[\mathrm{kJ}(\mathrm{mol})^{-1}\right]}\end{array}$ & $S^{\mathrm{o} \mathrm{a}}$ \\
\hline isobutene & -37.50 & $215.4^{\mathrm{b}}$ \\
methanol & -239.2 & 126.8 \\
ethanol & -277.6 & 160.7 \\
1-propanol & -302.6 & 193.6 \\
1-butanol & -327.3 & 225.8 \\
MTBE & -313.6 & 265.3 \\
ETBE & $\left.-349.9^{-1}\right]$ & $297.9^{\mathrm{c}}$ \\
PTBE & $-372.2^{\mathrm{b}}$ & $333.5^{\mathrm{b}}$ \\
BTBE & $-403.3^{\mathrm{c}}$ & $362.7^{\mathrm{d}}$ \\
\hline
\end{tabular}

${ }^{\mathrm{a}}$ Unless specified, values have been taken from $C R C$ Handbook of Chemistry and Physics ${ }^{46} .{ }^{\mathrm{b}}$ Linnekoski et al ${ }^{37}$. ${ }^{\mathrm{c}}$ Sharonov et al ${ }^{43}$. ${ }^{\mathrm{d}}$ Estimated by means of the Modified Benson Method ${ }^{21-23}$ 
“Table 4. Theoretically determined standard enthalpy, Gibbs free energy and entropy changes, and the corresponding thermodynamic equilibrium constants, for alkyl tert-butyl ether syntheses in the liquid phase at $298.15 \mathrm{~K} . "$

\begin{tabular}{lllll}
\hline \multirow{2}{*}{ Reaction } & $-\Delta_{r} H^{\mathrm{o}}$ & $-\Delta_{r} G^{\mathrm{o}}$ & $-\Delta_{r} S^{\mathrm{o}}$ & $K$ \\
& {$\left[\mathrm{~kJ}(\mathrm{~mol})^{-1}\right]$} & {$\left[\mathrm{kJ}(\mathrm{mol})^{-1}\right]$} & {$\left[\mathrm{J}(\mathrm{mol} \mathrm{K})^{-1}\right]$} & \\
\hline MTBE & -36.90 & -14.0 & -76.9 & 280 \\
ETBE & -34.80 & -11.5 & -78.2 & 103 \\
PTBE & -32.10 & -9.6 & -75.5 & 48 \\
BTBE & -38.50 & -15.1 & -78.6 & 438 \\
\hline
\end{tabular}


“Table 5. Measured reaction medium composition, with standard uncertainties, at equilibrium in the PTBE synthesis reaction ${ }^{\mathrm{a}}$ and calculated equilibrium constants, $K_{x}{ }^{\mathrm{b}}, K_{\gamma}{ }^{\mathrm{c}}$ and $K^{\mathrm{d}}$, for each experimental run. Experiments were carried out in the liquid phase at $2.00 \mathrm{MPa}$ (standard uncertainty: $0.03 \mathrm{MPa}$ ) in a batch stirred tank reactor from mixtures of different initial alcohol to olefin molar ratios, $\mathrm{R}_{\mathrm{A} / \mathrm{O}}^{\mathrm{O}}$. Standard uncertainties of the equilibrium constants have been estimated for each value by means of the Monte Carlo method ${ }^{41}$ with 1000 generated points applied to the chromatographic analysis results."

\begin{tabular}{|c|c|c|c|c|c|c|c|c|c|c|}
\hline \multirow{2}{*}{$\mathrm{T}[\mathrm{K}]^{\mathrm{e}}$} & \multirow{2}{*}{$\mathrm{R}_{\mathrm{A} / \mathrm{O}}^{\mathrm{f}}$} & \multicolumn{6}{|c|}{ Mass fraction, $\mathrm{w} \cdot 10^{3}$} & \multirow{2}{*}{$K_{x}$} & \multirow{2}{*}{$K_{\gamma} \cdot 10^{3}$} & \multirow{2}{*}{$K$} \\
\hline & & isobutene & 1-propanol & PTBE & TBA & TMP-1 & TMP-2 & & & \\
\hline 320.2 & 1.01 & $39.1 \pm 0.6$ & $33.7 \pm 0.5$ & $920.3 \pm 1.1$ & $6.94 \pm 0.17$ & 0 & $0 \pm 0$ & $188 \pm 5$ & $309.0 \pm 0.8$ & $58 \pm 2$ \\
\hline 321.2 & 1.01 & $24.4 \pm 0.3$ & $63.4 \pm 0.7$ & $907.2 \pm 1.0$ & $4.97 \pm 0.09$ & 0 & $0 \pm 0$ & $159 \pm 3$ & $363.0 \pm 1.1$ & $57.9 \pm 1.1$ \\
\hline 323.2 & 2.00 & $8.36 \pm 0.10$ & $350 \pm 3$ & $637 \pm 3$ & $0.99 \pm 0.02$ & $3.11 \pm 0.04$ & $0.518 \pm 0.008$ & $72.7 \pm 1.4$ & $701 \pm 3$ & $51.0 \pm 0.9$ \\
\hline 325.7 & 1.06 & $26.5 \pm 0.3$ & $78.0 \pm 0.7$ & $884.0 \pm 0.9$ & $3.02 \pm 0.04$ & $7.18 \pm 0.08$ & $1.40 \pm 0.02$ & $118 \pm 2$ & $387.0 \pm 1.0$ & $45.7 \pm 0.7$ \\
\hline 333.9 & 1.01 & $34.4 \pm 0.6$ & $74.1 \pm 1.1$ & $880 \pm 2$ & $1.34 \pm 0.03$ & $8.708 \pm 0.147$ & $1.86 \pm 0.04$ & $95 \pm 3$ & $388.9 \pm 1.4$ & $37.1 \pm 0.9$ \\
\hline 344.5 & 1.04 & $42.7 \pm 0.6$ & $101.5 \pm 1.5$ & $842 \pm 2$ & $0.79 \pm 0.02$ & $10.4 \pm 0.2$ & $2.28 \pm 0.05$ & $55.3 \pm 1.4$ & $439 \pm 2$ & $24.3 \pm 0.6$ \\
\hline 352.0 & 2.00 & $25.6 \pm 0.3$ & $358 \pm 3$ & $614 \pm 3$ & $0.658 \pm 0.012$ & $1.222 \pm 0.015$ & $0 \pm 0$ & $22.8 \pm 0.4$ & $712 \pm 2$ & $16.2 \pm 0.3$ \\
\hline 352.2 & 1.02 & $57.9 \pm 0.7$ & $110.1 \pm 1.4$ & $823 \pm 2$ & $0.81 \pm 0.02$ & $6.82 \pm 0.10$ & $1.53 \pm 0.03$ & $37.6 \pm 0.9$ & $454.8 \pm 1.4$ & $17.1 \pm 0.4$ \\
\hline
\end{tabular}

\footnotetext{
${ }^{a}$ Reaction R3 in Scheme $1 .{ }^{b}$ Equilibrium constant in terms of molar fractions. ${ }^{c}$ Equilibrium constant in terms of activity coefficients. ${ }^{d}$ Equilibrium constant in terms of activities. ${ }^{\mathrm{e}}$ Standard uncertainty: $0.06 \mathrm{~K} .{ }^{\mathrm{f}}$ Relative standard uncertainty: $0.5 \%$.
} 
“Table 6. Measured reaction medium composition, with standard uncertainties, at equilibrium in the BTBE synthesis reaction ${ }^{\mathrm{a}}$ and calculated equilibrium constants, $K_{x}{ }^{\mathrm{b}}, K_{\gamma}{ }^{\mathrm{c}}$ and $K^{\mathrm{d}}$, for each experimental run. Experiments were carried out in the liquid phase at $2.00 \mathrm{MPa}$ (standard uncertainty: $0.03 \mathrm{MPa}$ ) in a batch stirred tank reactor from mixtures of different initial alcohol to olefin molar ratios, $\mathrm{R}_{\mathrm{A} / \mathrm{O}}^{\mathrm{O}}$. Standard uncertainties of the equilibrium constants have been estimated for each value by means of the Monte Carlo method ${ }^{41}$ with 1000 generated points applied to the chromatographic analysis results."

\begin{tabular}{|c|c|c|c|c|c|c|c|c|c|}
\hline \multirow{2}{*}{$\mathrm{T}[\mathrm{K}]^{\mathrm{e}}$} & \multirow{2}{*}{$\mathrm{R}_{\mathrm{A} / \mathrm{O}}^{\mathrm{f}}{ }^{\mathrm{f}}}$. & \multicolumn{5}{|c|}{ Mass fraction, $\mathrm{w} \cdot 10^{3}$} & \multirow{2}{*}{$K_{x}$} & \multirow{2}{*}{$K_{\gamma} \cdot 10^{3}$} & \multirow{2}{*}{$K$} \\
\hline & & isobutene & 1-butanol & BTBE & TMP-1 & TMP-2 & & & \\
\hline 317.2 & 1.01 & $21.5 \pm 0.4$ & $72.8 \pm 1.3$ & $902 \pm 23.25 \pm 0.10$ & $0.410 \pm 0.008$ & $0.519 \pm 0.008$ & $153 \pm 5$ & $396 \pm 2$ & $60.7 \pm 1.6$ \\
\hline 323.4 & 1.01 & $24.1 \pm 0.3$ & $87.7 \pm 1.3$ & $880 \pm 2 \quad 1.37 \pm 0.03$ & $5.89 \pm 0.10$ & $1.241 \pm 0.015$ & $112 \pm 3$ & $423 \pm 2$ & $47.5 \pm 1.1$ \\
\hline 334.3 & 1.00 & $37.6 \pm 0.5$ & $95.2 \pm 1.3$ & $858 \pm 21.06 \pm 0.02$ & $6.84 \pm 0.10$ & $1.55 \pm 0.02$ & $66 \pm 2$ & $443 \pm 2$ & $29.3 \pm 0.6$ \\
\hline 343.5 & 1.20 & $36.9 \pm 0.7$ & $189 \pm 4$ & $769 \pm 4 \quad 1.18 \pm 0.04$ & $2.85 \pm 0.06$ & $0.662 \pm 0.011$ & $32.4 \pm 1.1$ & $576 \pm 4$ & $18.7 \pm 0.6$ \\
\hline 345.5 & 1.03 & $41.1 \pm 0.5$ & $159 \pm 2$ & $792 \pm 2 \quad 1.27 \pm 0.03$ & $5.50 \pm 0.08$ & $1.278 \pm 0.013$ & $35.1 \pm 0.8$ & $540 \pm 2$ & $19.0 \pm 0.4$ \\
\hline 353.9 & 2.01 & $23.8 \pm 0.3$ & $437 \pm 4$ & $536 \pm 40.87 \pm 0.02$ & $1.79 \pm 0.02$ & $0.402 \pm 0.004$ & $17.2 \pm 0.3$ & $816 \pm 2$ & $14.1 \pm 0.2$ \\
\hline 354.1 & 1.00 & $65.2 \pm 0.8$ & $128 \pm 2$ & $793 \pm 2 \quad 1.38 \pm 0.03$ & $10.0 \pm 0.2$ & $2.49 \pm 0.03$ & $27.6 \pm 0.6$ & $499 \pm 2$ & $13.8 \pm 0.3$ \\
\hline
\end{tabular}


"Table 7. Molar heat capacity coefficients of the equation $C_{P}^{o}\left[J \mathrm{~mol}^{-1} \mathrm{~K}^{-1}\right]=a+b T+c T^{2}+d T^{3}$, where $\mathrm{T}$ is expressed in $\mathrm{K} . "$

\begin{tabular}{lcccc}
\hline Compound & $\mathrm{a}$ & $\mathrm{b}$ & $\mathrm{c} \cdot 10^{3}$ & $\mathrm{~d} \cdot 10^{5}$ \\
\hline isobutene $^{\mathrm{a}}$ & 596.89 & -4.6357 & 14.40 & -1.372 \\
methanol $^{\mathrm{a}}$ & 1391.6 & -12.364 & 37.81 & -3.719 \\
ethanol $^{\mathrm{a}}$ & 1422.5 & -12.839 & 40.31 & -4.016 \\
1-propanol $^{\mathrm{b}}$ & 277.77 & -2.0498 & 7.476 & -0.7170 \\
1-butanol $^{\mathrm{b}}$ & 320.73 & -2.2142 & 7.986 & -0.7585 \\
MTBE $^{\mathrm{a}}$ & 53.176 & 0.7173 & -1.533 & 0.2241 \\
ETBE $^{\mathrm{a}}$ & 83.158 & 0.5894 & -0.864 & 0.1383 \\
PTBE $^{\mathrm{c}}$ & -539.7 & 4.279 & -5.96 & 0 \\
BTBE $^{\mathrm{c}}$ & -507.8 & 4.235 & -5.93 & 0
\end{tabular}

\footnotetext{
${ }^{\mathrm{a}}$ Izquierdo et al ${ }^{27} .{ }^{\mathrm{b}}$ Estimated by Missenard method ${ }^{20}$.

${ }^{\mathrm{c}}$ Determined by differential scanning calorimetry (DSC).
} 
"Table 8. Parameters that describe the temperature dependence of $K, \Delta_{r} H^{o}, \Delta_{r} S^{o}$, and $\Delta_{r} G^{o}$ (Eqs. 16, 13, 17 and 18, respectively) for the studied reactions when $\Delta_{r} H^{o}=f(\mathrm{~T})$. Expanded uncertainty for 95 percent level of confidence is provided for parameters $I_{K}$ and $I_{H}$ (coverage factor MTBE and BTBE: 2.57; ETBE: 2.05; PTBE: 2.45).”

\begin{tabular}{lcccccc}
\hline Reaction & $\begin{array}{c}\mathrm{a} \\
{\left[\mathrm{J} \mathrm{mol}^{-1} \mathrm{~K}^{-1}\right]}\end{array}$ & $\begin{array}{c}\mathrm{b} \\
{\left[\mathrm{J} \mathrm{mol}^{-1} \mathrm{~K}^{-2}\right]}\end{array}$ & $\begin{array}{c}\mathrm{c} \cdot 10^{3} \\
{\left[\mathrm{~J} \mathrm{~mol}^{-1} \mathrm{~K}^{-3}\right]}\end{array}$ & $\begin{array}{c}\mathrm{d} \cdot 10^{5} \\
{\left[\mathrm{~J} \mathrm{~mol}^{-1} \mathrm{~K}^{-4}\right]}\end{array}$ & $\begin{array}{c}\mathrm{I}_{\mathrm{K}} \cdot 10^{3} \\
{\left[\mathrm{~J} \mathrm{~mol}^{-1} \mathrm{~K}^{-1}\right]}\end{array}$ & $\begin{array}{c}\mathrm{I}_{\mathrm{H}} \\
{[-]}\end{array}$ \\
\hline MTBE & -1935.314 & 17.717 & -53.743 & 5.3151 & $122.5 \pm 9.9$ & $1145.2 \pm 3.5$ \\
ETBE & -1936.232 & 18.0641 & -55.574 & 5.5263 & $117.66 \pm 1.68$ & $1139.62 \pm 0.58$ \\
PTBE & -1414.36 & 10.9645 & -27.836 & 2.089 & $105.5 \pm 3.4$ & $864.31 \pm 1.21$ \\
BTBE & -1425.42 & 11.0849 & -28.316 & 2.1305 & $105.3 \pm 3.0$ & $870.35 \pm 1.08$ \\
\hline
\end{tabular}


"Table 9. Standard molar enthalpy $\left[\mathrm{kJ} \mathrm{mol}^{-1}\right]$, entropy $\left[\mathrm{J}(\mathrm{mol} \mathrm{K})^{-1}\right]$ and Gibbs free energy changes $\left[\mathrm{kJ} \mathrm{mol}^{-1}\right]$ of alkyl tert-butyl ether syntheses in the liquid phase at $298.15 \mathrm{~K}$. Expanded uncertainty for 95 percent level of confidence for experimental values is provided (coverage factor MTBE and BTBE: 2.57; ETBE: 2.05; PTBE: 2.45).”

\begin{tabular}{|c|c|c|c|c|c|c|c|c|}
\hline \multirow[t]{2}{*}{ Reaction } & \multirow{2}{*}{$\begin{array}{c}\text { Property } \\
\Delta_{r} H^{o}\end{array}$} & \multirow{2}{*}{$\begin{array}{r}\Delta_{r} H^{o} \neq f(\mathrm{~T}) \\
-38 \pm 10\end{array}$} & \multicolumn{2}{|c|}{$\Delta_{r} H^{o}=f(\mathrm{~T})$ Theoret. } & \multicolumn{4}{|c|}{ Literature } \\
\hline & & & $-37 \pm 10$ & -36.9 & $-37.7^{\mathrm{a}}$ & $-39.1 \pm 0.8^{b}$ & $-38.0 \pm 0.8^{b}$ & $-36.1^{c}$ \\
\hline \multirow[t]{3}{*}{ MTBE } & $\Delta_{r} S^{o}$ & $-80 \pm 30$ & $-80 \pm 30$ & -76.9 & & $-85.3 \pm 0.5^{b}$ & $-81.7 \pm 0.5^{b}$ & $-75.4^{\mathrm{c}}$ \\
\hline & $\Delta_{r} G^{o}$ & $-13 \pm 13$ & $-14 \pm 13$ & -14.0 & $-14.0^{\mathrm{a}}$ & $-13.7 \pm 0.8^{b}$ & $-13.6 \pm 0.8^{b}$ & $-13.7^{c}$ \\
\hline & $\Delta_{r} H^{o}$ & $-40.4 \pm 1.7$ & $-38.5 \pm 1.7$ & -34.8 & $-44.3 \pm 2^{d}$ & $-41.1^{\mathrm{e}}$ & $-35.45 \pm 1.94^{f}$ & $-36.3 \pm 7.2^{\mathrm{g}}$ \\
\hline \multirow[t]{3}{*}{ ETBE } & $\Delta_{y} S^{o}$ & $-95 \pm 5$ & $-89 \pm 5$ & -78.2 & & $-94.9^{\mathrm{e}}$ & $-82.37 \pm 5.99^{f}$ & $-81.3 \pm 21.4^{\mathrm{g}}$ \\
\hline & $\Delta_{r} G^{o}$ & $-12 \pm 2$ & $-12 \pm 2$ & -11.5 & & $-12.8^{\mathrm{e}}$ & & $-12.1 \pm 4.5^{\mathrm{g}}$ \\
\hline & $\Delta_{r} H^{o}$ & $-36 \pm 4$ & $-34 \pm 3$ & -32.1 & $-26.4^{h}$ & & & \\
\hline \multirow[t]{3}{*}{ PTBE } & $\Delta_{r} S^{o}$ & $-79 \pm 11$ & $-71 \pm 10$ & -75.5 & $-53.0^{\mathrm{h}}$ & & & \\
\hline & $\Delta_{r} G^{o}$ & $-13 \pm 5$ & $-12 \pm 4$ & -9.6 & & & & \\
\hline & $\Delta_{r} H^{o}$ & $-38 \pm 3$ & $-35 \pm 3$ & -38.5 & $-34.8 \pm 2.7^{1}$ & & & \\
\hline \multirow[t]{2}{*}{ ВTВE } & $\Delta_{r} S^{o}$ & $-86 \pm 8$ & $-76 \pm 9$ & -78.6 & $-75.8 \pm 7.7^{\mathrm{i}}$ & & & \\
\hline & $\Delta_{r} G^{o}$ & $-12 \pm 4$ & $-12 \pm 4$ & -15.1 & & & & \\
\hline
\end{tabular}


“Table 10. Readjusted thermochemical data of the ethers produced if $\Delta_{r} H^{o}=f(\mathrm{~T})$ (standard state, liquid at 1 atm and $298.15 \mathrm{~K}) . ”$

\begin{tabular}{lll}
\hline Compound & $\begin{array}{l}\Delta_{f} H^{\mathrm{o}}\left(\text { difference with }_{\text {literature value }}^{\mathrm{a}}\right) \\
{\left[\mathrm{kJ}(\mathrm{mol})^{-1}\right]}\end{array}$ & $\begin{array}{l}S^{o} \text { (difference with } \\
\text { literature/estimated }_{\left.\text {value }^{\mathrm{a}}\right)\left[\mathrm{J}(\mathrm{mol} \mathrm{K})^{-1}\right]}\end{array}$ \\
\hline MTBE & $-313.5(0.0 \%)$ & $264.5(-0.3 \%)$ \\
ETBE & $-353.6(1.1 \%)$ & $286.7(-3.9 \%)$ \\
PTBE & $-373.6(0.4 \%)$ & $338.5(1.5 \%)$ \\
BTBE & $-399.8(-0.9 \%)$ & $365.0(0.6 \%)$ \\
\hline
\end{tabular}

${ }^{a}$ Relative difference of readjusted formation data compared to values in Table 3.

"Table 11. Calculated values of the liquid-phase standard molar enthalpy change of reaction, $\Delta_{r} H^{o}$, for the studied reactions, when it is considered as temperature dependent (Eq. 13)."

\begin{tabular}{lllll}
\hline \multirow{2}{*}[\mathrm{K}]{} & \multicolumn{4}{c}{$\Delta_{r} H^{o}\left[\mathrm{~kJ} \mathrm{~mol}^{-1}\right]$} \\
\cline { 2 - 5 } & MTBE & ETBE & PTBE & BTBE \\
\hline 323 & -37.5 & -39.3 & -35.2 & -36.9 \\
333 & -37.8 & -39.7 & -36.0 & -37.8 \\
343 & -38.1 & -40.2 & -36.8 & -38.7 \\
353 & -38.5 & -40.7 & -37.7 & -39.7 \\
\hline
\end{tabular}




\section{ASSOCIATED CONTENT}

Supporting Information. PTBE and BTBE mass spectra are provided in Figures S1 and S2, respectively. Experimental conditions and results for each individual run in MTBE and ETBE experiments are provided in Tables S1 to S3. This material is available free of charge via the Internet at http://pubs.acs.org.

\section{AUTHOR INFORMATION}

\section{Corresponding Author}

*Email address: fite@ub.edu

\section{ACKNOWLEDGEMENTS}

The authors thank Rohm and Haas France, Purolite and Lanxess for providing the ion exchange resins used in this work. 


\section{REFERENCES}

(1) Nemec, L.; Blum, V.; Rinke, P.; Scheffler, M. Thermodynamic Equilibrium Conditions of Graphene Films on SiC. Phys. Rev. Lett. 2013, 111 (6), 065502.

(2) Zhao, G.; Li, J.; Wang, X. Kinetic and Thermodynamic Study of 1-Naphthol Adsorption from Aqueous Solution to Sulfonated Graphene Nanosheets. Chem. Eng. J. 2011, 173 (1), 185-190.

(3) Martinez, M.; Ahmed, A. H.; Loh, A. P.; Oswald, R. E. Thermodynamics and Mechanism of the Interaction of Willardiine Partial Agonists with a Glutamate Receptor: Implications for Drug Development. Biochemistry 2014.

(4) Wöhri, A. B.; Hillertz, P.; Eriksson, P.-O.; Meuller, J.; Dekker, N.; Snijder, A. Thermodynamic Studies of Ligand Binding to the Human Homopentameric Glycine Receptor Using Isothermal Titration Calorimetry. Mol. Membr. Biol. 2013, 30 (2), 169183.

(5) Sohel, M. I.; Jack, M. W. Thermodynamic Analysis of Lignocellulosic Biofuel Production via a Biochemical Process: Guiding Technology Selection and Research Focus. Bioresour. Technol. 2011, 102 (3), 2617-2622.

(6) Mortensen, P. M.; Grunwaldt, J. D.; Jensen, P. A.; Knudsen, K. G.; Jensen, A. D. A Review of Catalytic Upgrading of Bio-Oil to Engine Fuels. Appl. Catal. A Gen. 2011, 407 (1-2), 1-19.

(7) Nanda, M. R.; Yuan, Z.; Qin, W.; Ghaziaskar, H. S.; Poirier, M.-A.; Xu, C. C. Thermodynamic and Kinetic Studies of a Catalytic Process to Convert Glycerol into Solketal as an Oxygenated Fuel Additive. Fuel 2014, 117, 470-477.

(8) Snelling, J.; Barnett, M. O.; Zhao, D.; Arey, J. S. Methyl Tertiary Hexyl Ether and Methyl Tertiary Octyl Ether as Gasoline Oxygenates: Assessing Risks from Atmospheric Dispersion and Deposition. J. Air Waste Manage. Assoc. 2006, 56 (10), 1484-1492.

(9) Piel, W. J. Diversify Future Fuel Needs with Ethers. Fuel Reformul. 1994, 4 (2), $28-33$.

(10) Pérez, M. A.; Bringué, R.; Iborra, M.; Tejero, J.; Cunill, F. Ion Exchange Resins as Catalysts for the Liquid-Phase Dehydration of 1-Butanol to Di-N-Butyl Ether. Appl. 
Catal. A Gen. 2014, 482, 38-48.

(11) Gwynn, B. H.; Hirsch, J. H. Production of Alcohols by Oxo Process. US2743302 A, April 24, 1956.

(12) Gubisch, D.; Armbrust, K.; Kaizik, A.; Scholz, B.; Nehring, R. Process for the Production of Higher Oxo Alcohols. US6015928 A, 2000.

(13) Tsuchida, T.; Sakuma, S.; Takeguchi, T.; Ueda, W. Direct Synthesis of N -Butanol from Ethanol over Nonstoichiometric Hydroxyapatite. Ind. Eng. Chem. Res. 2006, 45 (25), 8634-8642.

(14) Pfromm, P. H.; Amanor-Boadu, V.; Nelson, R.; Vadlani, P.; Madl, R. Bio-Butanol vs. Bio-Ethanol: A Technical and Economic Assessment for Corn and Switchgrass Fermented by Yeast or Clostridium Acetobutylicum. Biomass and Bioenergy 2010, 34 (4), 515-524.

(15) Iborra, M.; Tejero, J.; Cunill, F.; Izquierdo, J. F.; Fité, C. Drying of Acidic Macroporous Styrene-Divinylbenzene Resins with 12-20 Cross-Linking Degree. Ind. Eng. Chem. Res. 2000, 39 (5), 1416-1422.

(16) Gmehling, J.; Li, J.; Schiller, M. A Modified UNIFAC Model. 2. Present Parameter Matrix and Results for Different Thermodynamic Properties. Ind. Eng. Chem. Res. 1993, 32 (1), 178-193.

(17) Vila, M.; Cunill, F.; Izquierdo, J.-F.; González, J.; Hernández, A. The Role of by-Products Formation in Methyltert-Butyl Ether Synthesis Catalyzed by a Macroporous Acidic Resin. Appl. Catal. A Gen. 1994, 117 (2), L99-L108.

(18) Tejero, J.; Calderón, A.; Cunill, F.; Izquierdo, J. F.; Iborra, M. The Formation of Byproducts in the Reaction of Synthesis of Isopropyl Tert-Butyl Ether from Isopropyl Alcohol and Isobutene on an Acidic Macroporous Copolymer. React. Funct. Polym. 1997, $33(2-3), 201-209$.

(19) Badia, J. H.; Fité, C.; Bringué, R.; Ramírez, E.; Cunill, F. Byproducts Formation in the Ethyl Tert-Butyl Ether (ETBE) Synthesis Reaction on Macroreticular Acid Ion-Exchange Resins. Appl. Catal. A Gen. 2013, 468, 384-394.

(20) Reid, R. C.; Prausnitz, J. M.; Poling, B. E. The Properties of Gases and Liquids, $4^{\text {th }}$ ed.; McGraw-Hill: New York, 1987. 
(21) Poling, B. E.; Prausnitz, J. M.; John Paul, O.; Reid, R. C. The Properties of Gases and Liquids, $5^{\text {th }}$ ed.; McGraw-Hill: New York, 2001.

(22) Domalski, E. S.; Hearing, E. D. Estimation of the Thermodynamic Properties of Hydrocarbons at 298.15 K. J. Phys. Chem. Ref. Data 1988, 17 (4), 1637.

(23) Domalski, E. S.; Hearing, E. D. Estimation of the Thermodynamic Properties of C-H-NO-S-Halogen Compounds at 298.15 K. J. Phys. Chem. Ref. Data 1993, 22 (4), 805-1159.

(24) Colombo, F.; Cori, L.; Dalloro, L.; Delogu, P. Equilibrium Constant for the Methyl TertButyl Ether Liquid-Phase Synthesis Using UNIFAC. Ind. Eng. Chem. Fundam. 1983, 22 (2), 219-223.

(25) Rehfinger, A.; Hoffmann, U. Kinetics of Methyl Tertiary Butyl Ether Liquid Phase Synthesis Catalyzed by Ion Exchange resin-I. Intrinsic Rate Expression in Liquid Phase Activities. Chem. Eng. Sci. 1990, 45 (6), 1605-1617.

(26) Izquierdo, J. F.; Cunill, F.; Vila, M.; Tejero, J.; Iborra, M. Equilibrium Constants for Methyl Tert-Butyl Ether Liquid-Phase Synthesis. J. Chem. Eng. Data 1992, 37 (3), 339343.

(27) Izquierdo, J. F.; Cunill, F.; Vila, M.; Iborra, M.; Tejero, J. Equilibrium Constants for Methyl Tert-Butyl Ether and Ethyl Tert-Butyl Ether Liquid-Phase Syntheses Using C4 Olefinic Cut. Ind. Eng. Chem. Res. 1994, 33 (11), 2830-2835.

(28) Zhang, T.; Datta, R. Integral Analysis of Methyl Tert-Butyl Ether Synthesis Kinetics. Ind. Eng. Chem. Res. 1995, 34 (3), 730-740.

(29) Wyczesany, A. Thermodynamics of Ether Production. In Handbook of MTBE and Other Gasoline Oxygenates; Hamid, H., Ali, M. A., Eds.; Marcel Dekker, Inc.: New York, 2004.

(30) Solà, L.; Pericàs, M. A.; Cunill, F.; Iborra, M. Reaction Calorimetry Study of the LiquidPhase Synthesis of Tert-Butyl Methyl Ether. Ind. Eng. Chem. Res. 1994, 33 (11), 25782583.

(31) Françoisse, O.; Thyrion, F. C. Kinetics and Mechanism of Ethyl Tert-Butyl Ether LiquidPhase Synthesis. Chem. Eng. Process. Process Intensif. 1991, 30 (3), 141-149. 
(32) Vila, M.; Cunill, F.; Izquierdo, J. F.; Tejero, J.; Iborra, M. Equilibrium Constants for Ethyl Tert-Butyl Ether Liquid-Phase Synthesis. Chem. Eng. Commun. 1993, 124 (1), 223-232.

(33) Jensen, K. L.; Datta, R. Ethers from Ethanol. 1. Equilibrium Thermodynamic Analysis of the Liquid-Phase Ethyl Tert-Butyl Ether Reaction (ETBE). Ind. Eng. Chem. Res. 1995, 34 (1), 392-399.

(34) Sharonov, K. G.; Rozhnov, A. M.; Korol'kov, A. V.; Karaseva, S. Y.; Miroshnichenko, E. A.; Korchatova, L. I. Enthalpies of Formation of 2-Methyl-2-Ethoxypropane and 2-Ethyl2-Ethoxypropane from Equilibrium Measurements. J. Chem. Thermodyn. 1995, 27 (7), 751-753.

(35) Gómez, C.; Cunill, F.; Iborra, M.; Izquierdo, F.; Tejero, J. Experimental Study of the Simultaneous Synthesis of Methyl Tert -Butyl Ether and Ethyl Tert -Butyl Ether in Liquid Phase. Ind. Eng. Chem. Res. 1997, 36 (11), 4756-4762.

(36) Soto, R.; Fité, C.; Ramírez, E.; Bringué, R.; Cunill, F. Equilibrium of the Simultaneous Etherification of Isobutene and Isoamylenes with Ethanol in Liquid-Phase. Chem. Eng. Res. Des. 2014, 92 (4), 644-656.

(37) Linnekoski, J. A.; Krause, A. O. I.; Holmen, A.; Kjetså, M.; Moljord, K. Etherification of Isobutene with 1-Propanol and 2-Propanol. Appl. Catal. A Gen. 1998, 174 (1-2), 1-11.

(38) Macho, V.; Kavala, M.; Polievka, M.; Okresa, M.; Piecka, W. Production of Alkyl TertButyl Ethers. Ropa Uhlie 1982, 24, 397.

(39) Ancillotti, F.; Massi Mauri, M.; Pescarollo, E. Ion Exchange Resin Catalyzed Addition of Alcohols to Olefins. J. Catal. 1977, 46 (1), 49-57.

(40) Slomkiewicz, P. M. The Gas Phase N-Propyl-Tert-Butyl Ether Synthesis. Appl. Catal. A Gen. 2006, 313 (1), 74-85.

(41) Ogilvie, J. F. A Monte-Carlo Approach to Error Propagation. Comput. Chem. 1984, 8 (3), 205-207.

(42) Sharonov, K. G.; Mishentseva, Y. B.; Rozhnov, A. M.; Miroshnichenko, E. A.; Korchatova, L. I. Molar Enthalpies of Formation and Vaporization of T-Butoxybutanes and Thermodynamics of Their Synthesis from a Butanol and 2-Methylpropene I. Equilibria of Synthesis Reactions of T-Butoxybutanes in the Liquid Phase. J. Chem. 
Thermodyn. 1991, 23 (2), 141-145.

(43) Sharonov, K. G.; Mishentseva, Y. B.; Rozhnov, A. M.; Miroshnichenko, E. A.; Korchatova, L. I. Molar Enthalpies of Formation and Vaporization of T-Butoxybutanes and Thermodynamics of Their Synthesis from a Butanol and 2-Methylpropene: 2. Enthalpies of Combustion and Vaporization of T-Butoxybutanes. J. Chem. Thermodyn. 1991, 23 (7), 636-642.

(44) Domalski, E. S.; Hearing, E. D. Condensed Phase Heat Capacity Data. In NIST Chemistry WebBook, NIST Standard Reference Database Number 69; Linstrom, P. J., Mallard, W. G., Eds.; National Institute of Standards and Technology: Gaithersburg MD, 20899, 20899.

(45) Fisher, S.; Kunin, R. Routine Exchange Capacity Determinations of Ion Exchange Resins. Anal. Chem. 1955, 27 (7), 1191-1194.

(46) Lide, D. R. CRC Handbook of Chemistry and Physics, $85^{\text {th }}$ ed.; CRC Press: Boca Raton, FL, 2004. 